\title{
Preclinical performance of a pediatric mechanical circulatory support device: The PediaFlow ventricular assist device
}

\author{
Salim E. Olia, BSE, ${ }^{\mathrm{a}, \mathrm{b}, \mathrm{c}}$ Peter D. Wearden, MD, PhD, ${ }^{\mathrm{a}, \mathrm{b}, \mathrm{d}, \mathrm{e}}$ Timothy M. Maul, PhD, CCP,, $\mathrm{a,b,d,e}$ \\ Venkat Shankarraman, PhD, ${ }^{\mathrm{b}}$ Ergin Kocyildirim, MD, ${ }^{\mathrm{b}, \mathrm{d}}$ Shaun T. Snyder, BS, ${ }^{\mathrm{f}}$ \\ Patrick M. Callahan, MD, ${ }^{\mathrm{b}, \mathrm{d}, \mathrm{g}}$ Marina V. Kameneva, $\mathrm{PhD},{ }^{\mathrm{a}, \mathrm{b}, \mathrm{h}}$ William R. Wagner, $\mathrm{PhD},{ }^{\mathrm{a}, \mathrm{b}, \mathrm{h}, \mathrm{i}}$ \\ Harvey S. Borovetz, PhD, ${ }^{\mathrm{a}, \mathrm{b}, \mathrm{h}, \mathrm{i}}$ and James F. Antaki, $\mathrm{PhD}^{\mathrm{b}, \mathrm{j}}$
}

\section{ABSTRACT}

Objectives: The PediaFlow (HeartWare International, Inc, Framingham, Mass) is a miniature, implantable, rotodynamic, fully magnetically levitated, continuousflow pediatric ventricular assist device. The fourth-generation PediaFlow was evaluated in vitro and in vivo to characterize performance and biocompatibility.

Methods: Supported by 2 National Heart, Lung, and Blood Institute contract initiatives to address the limited options available for pediatric patients with congenital or acquired cardiac disease, the PediaFlow was developed with the intent to provide chronic cardiac support for infants as small as $3 \mathrm{~kg}$. The University of Pittsburgh-led Consortium evaluated fourth-generation PediaFlow prototypes both in vitro and within a preclinical ovine model $(n=11)$. The latter experiments led to multiple redesigns of the inflow cannula and outflow graft, resulting in the implantable design represented in the most recent implants $(n=2)$.

Results: With more than a decade of extensive computational and experimental efforts spanning 4 device iterations, the AA battery-sized fourth-generation PediaFlow has an operating range of 0.5 to $1.5 \mathrm{~L} / \mathrm{min}$ with minimal hemolysis in vitro and excellent hemocompatibility (eg, minimal hemolysis and platelet activation) in vivo. The pump and finalized accompanying implantable components demonstrated preclinical hemodynamics suitable for the intended pediatric application for up to 60 days.

Conclusions: Designated a Humanitarian Use Device for "mechanical circulatory support in neonates, infants, and toddlers weighing up to $20 \mathrm{~kg}$ as a bridge to transplant, a bridge to other therapeutic intervention such as surgery, or as a bridge to recovery" by the Food and Drug Administration, these initial results document the biocompatibility and potential of the fourth-generation PediaFlow design to provide chronic pediatric cardiac support. (J Thorac Cardiovasc Surg 2018;156:1643-51)

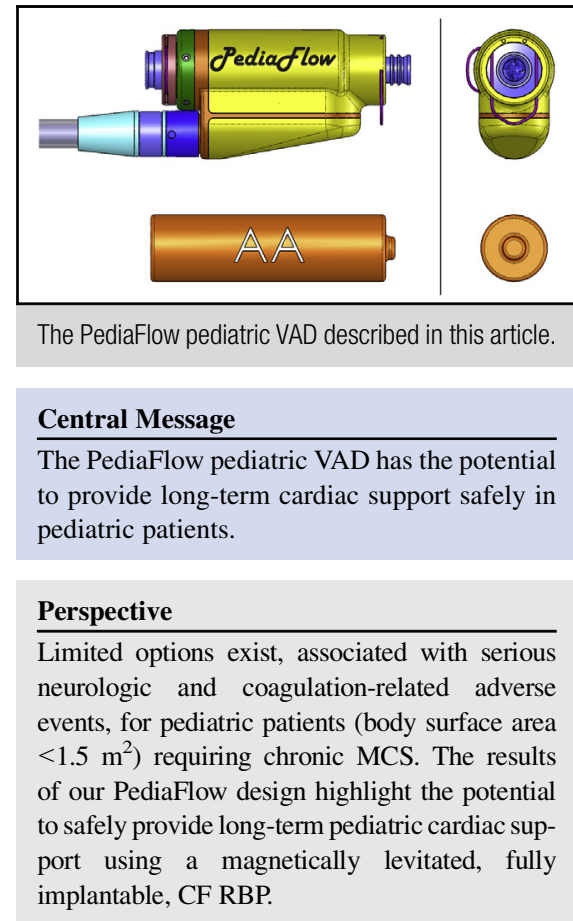

See Editorial Commentary page 1652.

See Editorial page 1642.
From the Departments of ${ }^{\mathrm{a} B i o e n g i n e e r i n g, ~}{ }^{\mathrm{e}}$ Cardiothoracic Surgery, ${ }^{\mathrm{g}}$ Anesthesiology, ${ }^{\mathrm{h}}$ Surgery, and ${ }^{\mathrm{i}}$ Chemical and Petroleum Engineering, and ${ }^{\mathrm{b}} \mathrm{McGowan}$ Institute for Regenerative Medicine, University of Pittsburgh, Pittsburgh, Pa; ${ }^{\mathrm{c}}$ Artificial Heart Program, and 'Children's Hospital of Pittsburgh, University of Pittsburgh Medical Center, Pittsburgh, Pa; ${ }^{\mathrm{f}}$ LaunchPoint Technologies LLC, Goleta, Calif; ${ }^{\mathrm{j}}$ Department of Biomedical Engineering, Carnegie Mellon University, Pittsburgh, $\mathrm{Pa}$.

The current affiliation of Drs Wearden and Maul is Cardiothoracic Surgery, Nemours Children's Hospital, Orlando, Fla. Dr Antaki's current affiliation is Department of Biomedical Engineering, Cornell University, Ithaca, NY

This work was supported by the National Heart, Lung, and Blood Institute under 2 contract awards - Pediatric Circulatory Support (N01-HV-48192; H.S.B. Principal Investigator) and Pumps for Kids, Infants and Neonates - Preclinical Program
(N01-HV-00235; H.S.B. Principal Investigator); and National Institute of Child Health and Human Development award "Development of the PediaFlow Pediatric Ventricular Assist Device” (5RC1HD064041-02; P.D.W. - Principal Investigator). S.E.O. was supported in part by the National Institutes of Health T32-HL076124 Cardiovascular Bioengineering Training Program.

Received for publication April 28, 2016; revisions received March 23, 2018; accepted for publication April 11, 2018; available ahead of print May 25, 2018.

Address for reprints: James F. Antaki, PhD, Cornell University, 109 Weill Hall, Ithaca, NY 14853 (E-mail: antaki@cornell.edu).

$0022-5223 / \$ 36.00$

Copyright (C) 2018 by The American Association for Thoracic Surgery

https://doi.org/10.1016/j.jtcvs.2018.04.062 


\section{Abbreviations and Acronyms}

$\mathrm{CF}=$ continuous-flow

FDA $=$ Food and Drug Administration

$\mathrm{LV}=$ left ventricle

MCS = mechanical circulatory support

$\mathrm{NIH}=$ normalized index of hemolysis

NHLBI $=$ National Heart Lung and Blood Institute

PF3 = third-generation PediaFlow

PF4 = fourth-generation PediaFlow

$\mathrm{RBP}=$ rotary blood pump

$\mathrm{RPM}=$ revolutions per minute

$\mathrm{VAD}=$ ventricular assist device

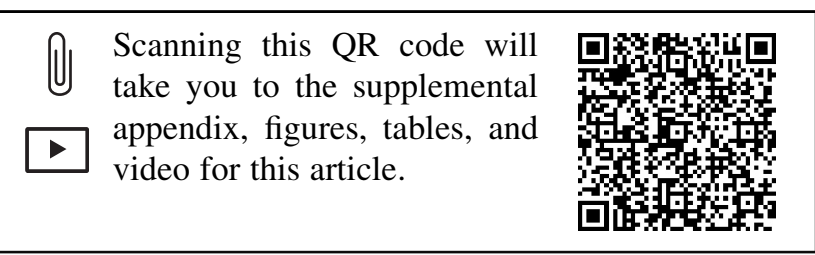

\section{HEART FAILURE IN ADULTS}

Heart disease is the leading cause of mortality in adults internationally and domestically, responsible for 1 in every 7 deaths within the United States. ${ }^{1}$ With circulatory assist device development spanning more than 5 decades for adults, multiple paradigm shifts from pulsatile total artificial hearts, to pulsatile (first generation) ventricular assist devices (VADs), to continuous-flow (CF) rotary blood pumps (RBPs) have revolutionized the field of mechanical circulatory support (MCS) in adults. By using centrifugal- or axial-flow designs with a single moving impeller, RBPs eliminate the flexible blood membranes, check valves, long cannulas, and tortuous blood paths required in prior pulsatile pumps. This increased simplicity allows for smaller blood-contacting surface area and reduced dead space, thereby reducing thrombosis potential and infection risks, in addition to decreasing the overall device size. ${ }^{2}$ Likewise, controller size has been markedly reduced by the elimination of large percutaneous drivelines, compressors, vacuum pumps, solenoids, and large power supplies associated with positive-displacement VADs. ${ }^{3}$ Supported by blood bearings/seals (second generation) or suspended by hydrodynamic or electromagnetic forces (third generation), RBPs are now the standard for chronic MCS support clinically. ${ }^{3,4}$ With multiple adult CF VADs approved by the Food and Drug Administration (FDA) for bridge-totransplant or destination therapy applications, these technologies have rescued thousands of adults with refractory end-stage heart failure with additional devices under development or in clinical trials. ${ }^{5}$

\section{PEDIATRIC HEART FAILURE}

Within the United States, $25 \%$ of all neonates born with a congenital heart defect will require invasive treatment within the first 12 months of life. ${ }^{6}$ Approximately 1800 infants die of congenital heart disease each year, and an additional 350 develop cardiomyopathy. ${ }^{7,8}$ Children weighing less than $15 \mathrm{~kg}$ listed for cardiac transplantation have the highest waiting list mortality rate $(17 \%)$ in all solid-organ transplantation categories. ${ }^{9}$ Cardiac transplantation remains the standard of care for refractory heart failure, but with limited donor availability, only $56 \%$ of infants listed received an organ over the last decade. ${ }^{10}$ Although MCS has successfully decreased waiting list mortality and has been used as a bridge-torecovery, availability of MCS devices for children remains limited. ${ }^{11,12}$

\section{MECHANICAL CIRCULATORY SUPPORT FOR PEDIATRICS}

Extracorporeal membrane oxygenation is used extensively for providing temporary cardiac support to children from neonates to adolescents. Although resource intensive, it is cost-effective, institutionally available, and rapidly initiated. ${ }^{13}$ However, extracorporeal membrane oxygenation is indicated only for short durations requiring immobilization and sedation, and has a high complication rate related to bleeding and thromboembolism proportional to support length. ${ }^{14}$ For adolescents with sufficient body surface area, the use of adult-indicated durable CF-VADs is supported by the PediMACs registry with a 6-month survival approaching $90 \%(\mathrm{n}=126)$ since inception in $2012 .{ }^{15}$ The majority of CF-VADs were implanted in patients 6 years of age or older because of device size, although there is a growing off-label use of the smaller HeartWare HVAD (Framingham, Mass) typically implanted with an outflow graft constriction or operated at lower speeds (revolutions per minute [RPM]) to maintain pediatric-appropriate flow rates ${ }^{15-17}$ in younger patients. Unlike adults, however, currently the only FDAapproved pediatric-specific bridge-to-transplant MCS device is the Berlin Heart EXCOR (Berlin, Germany), a paracorporeal, pneumatically driven, pulsatile VAD that provides extended support for the pediatric population through the use of varying volume-sized pumps coupled to a large pneumatic driver. The potential of the EXCOR as a lifesaving technology for children with heart failure is reflected in our center's experience since $2004 .{ }^{18}$ However, the EXCOR has a substantial risk profile with approximately $80 \%$ of patients experiencing at least 1 significant adverse event, the majority $(\sim 50 \%)$ from severe bleeding or infection, and is associated with frequent pump exchanges due to device thrombosis around the valve leaflets. ${ }^{19}$ 


\section{MATERIALS AND METHODS}

\section{Government Initiatives}

Although there continues to be a need for next-generation pediatric MCS technology, the small market potential has limited commercial interest. Driven by the lack of progress for this underserved population, the National Heart, Lung, and Blood Institute's (NHLBI) Pediatric Circulatory Support Program awarded more than \$22 million in 2004 to 5 separate consortia toward the development of novel pediatric MCS devices. ${ }^{11}$ In 2010, NHLBI launched the Pumps for Kids, Infants, and Neonates (PumpKIN) Pre-Clinical Program and awarded contracts (\$24 million) to support 4 preclinical efforts (3 for pediatric devices funded under Pediatric Circulatory Support Program) to gain Investigational Device Exemption from the FDA. ${ }^{20}$ The PediaFlow Consortium, consisting of the University of Pittsburgh, Children's Hospital of Pittsburgh, Carnegie Mellon University, and LaunchPoint Technologies (Goleta, Calif), received an award in both NHLBI Programs.

\section{PediaFlow Development}

As a participant in both NHLBI programs, we designed an implantable, mixed-flow, fully magnetically levitated (maglev), rotodynamic VAD to support the smallest (body surface area $<0.5 \mathrm{~m}^{2}$ with a cardiac index $>3.0 \mathrm{~L} / \mathrm{min} / \mathrm{m}^{2}$ ), and consequently most vulnerable, patients, for durations consistent with bridge-to-transplant wait list times, with the objective of minimizing MCS-associated serious adverse events. ${ }^{9,21}$ From the first prototype (PF1) demonstrating the feasibility and biocompatibility of a de novo, miniature maglev pump, the developmental evolution and miniaturization of the PediaFlow pediatric VAD (HeartWare International) summarized in Figure 1 involved implementation of turbomachinery principles outside of the usual operational ranges. ${ }^{22,23}$ Designed to operate at supercritical speeds (RPMs above resonance frequencies), the thirdgeneration PediaFlow (PF3) demonstrated excellent biocompatibility in vivo but maglev suspension instabilities limited flow rates to less than $1.0 \mathrm{~L} / \mathrm{min}$, necessitating further optimization and development. ${ }^{23}$

Intended to provide up to 6 months of circulatory support for patients between 3 and $15 \mathrm{~kg}$ at flow rates of 0.3 to $1.5 \mathrm{~L} / \mathrm{min}$, the fourthgeneration PediaFlow ( $\mathrm{PF} 4)$ pediatric VAD is the result of more than 10 years of biomedical, mechanical, electrical, and computational engineering. Representing the latest pump topology designed to achieve the target flow rates, the PF4's optimized blood-flow path consists of a tapered cylindrical impeller with 4 blades on the conical inlet face, leading to a single 1.5-mm annular fluid gap region, before passing through a 3-vane flow straightener machined into the aft-housing upon exit. ${ }^{24}$ Integrated "quickconnect" coupling mechanisms, recessed within the housing, enable direct attachment to the pump inlet and outlet (Figure 1, inset). Approximately the size of AA battery, a decrease in size of approximately $75 \%$ from the initial PF1 prototype (Figure 2, A), anatomic fit simulations suggest that the PF4 can be fully implanted in infants as small as $5 \mathrm{~kg}$ through placement behind the left rectus abdominus muscle with a single percutaneous driveline for electrical power.
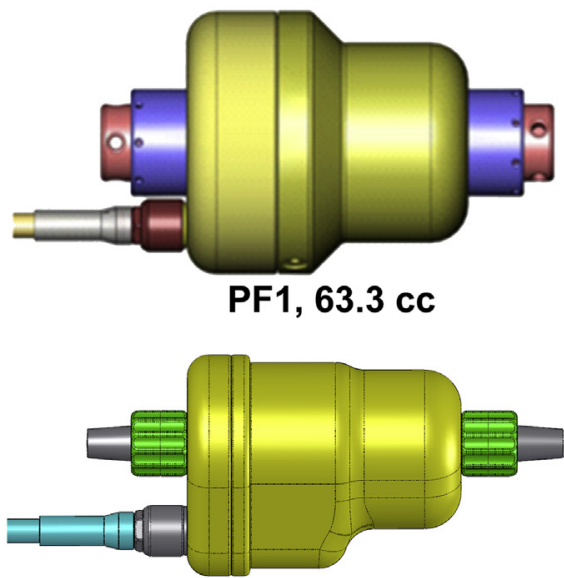

PF2, $34.4 \mathrm{cc}$

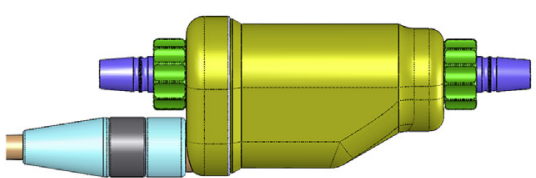

PF3, 16.3 cc

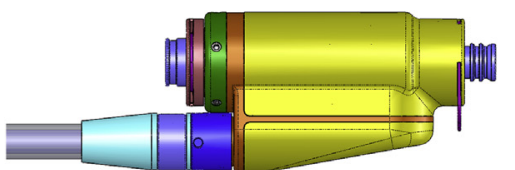

PF4, 16.0 cc

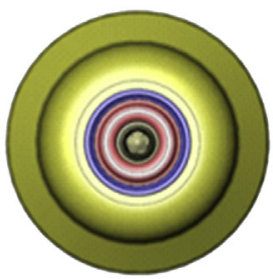

$44.0 \mathrm{~mm}$

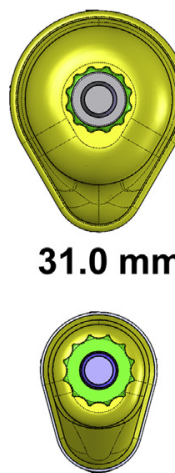

$20.3 \mathrm{~mm}$

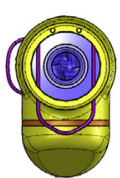

$17.5 \mathrm{~mm}$

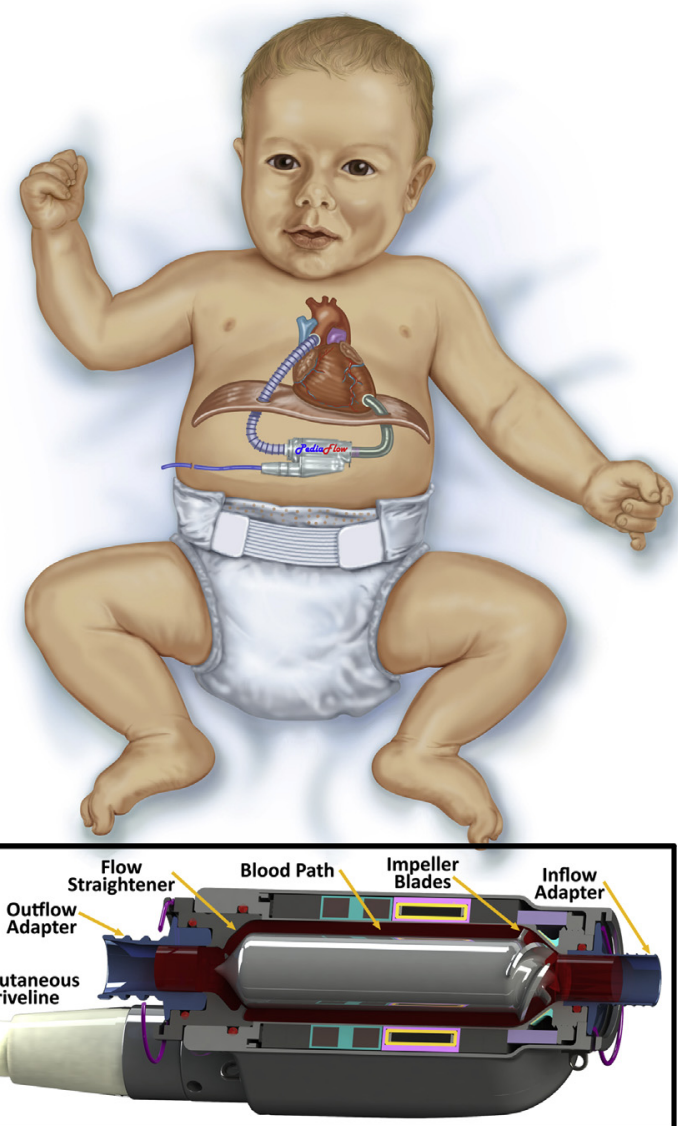

FIGURE 1. Evolution and miniaturization of the PediaFlow from the PF1 to the PF4 pediatric VAD and pump topology (inset). PF1, First-generation PediaFlow; $P F 2$, second-generation PediaFlow; $P F 3$, third-generation PediaFlow; $P F 4$, fourth-generation PediaFlow. 

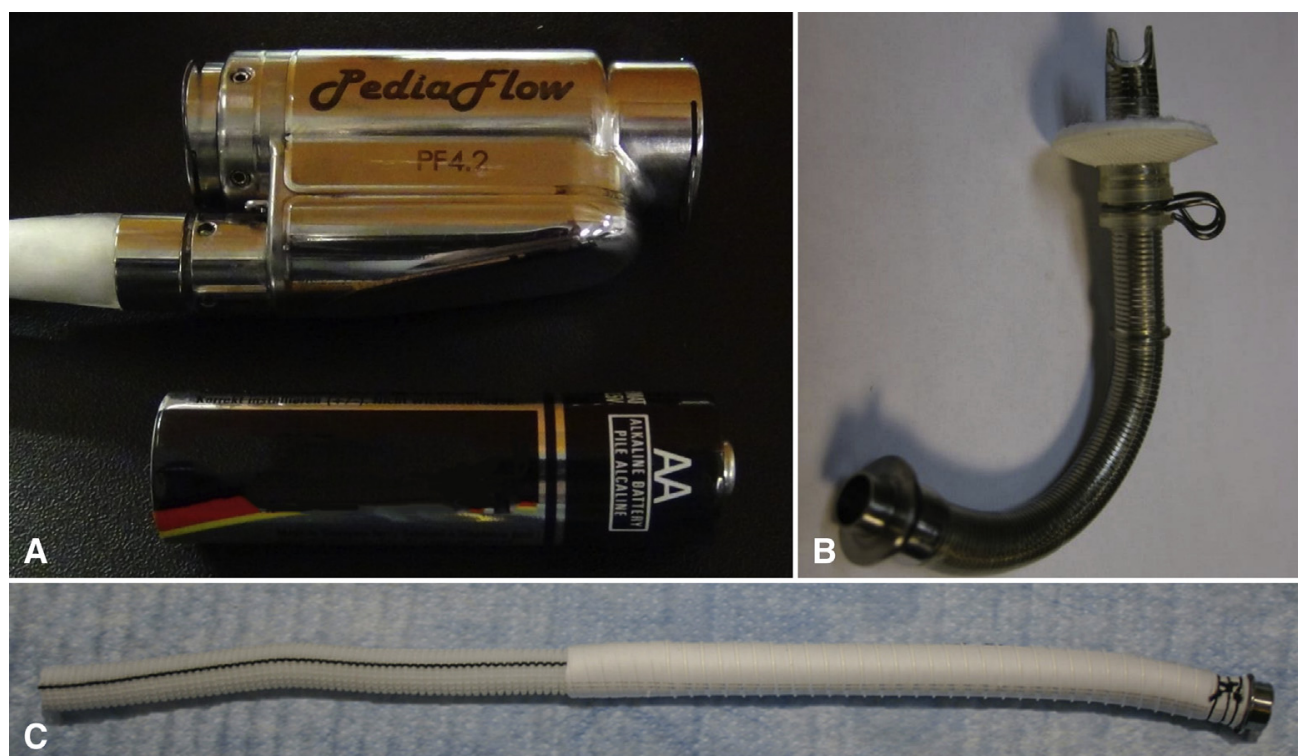

FIGURE 2. The PF4 prototype and implantable components: A, The PF4 pump and size comparison (AA battery). B, The parabolic-tip inflow cannula with detachable sewing ring. C, The preassembled 6-mm outflow graft assembly.

\section{In Vitro Assessment}

Benchtop evaluation of the PF4 was performed to confirm hemodynamic performance and characterize hemolysis potential. Physiologic flow rate and pressure measurements were simulated in a closed flow loop using a 2.39 centipoise blood analog glycerol-solution to generate characteristic pump "H-Q" curves following previously published methods. ${ }^{22}$ By using accepted standards, in vitro hemolysis testing was performed on several PF4 prototypes (Table E1 in Appendix E1) before in vivo implantation using purchased, citrated ovine whole blood (Lampire Inc, Ottsville, Pa) with a minimum total plasma protein concentration of $6.0 \mathrm{~g} / \mathrm{dL}$ within 3 days of venipuncture. ${ }^{25-28}$ The clinically used, centrifugal PediMag (Thoratec, Pleasanton, Calif) pump served as a control for comparison. The Normalized Index of Hemolysis (NIH) was calculated for each pediatric hemodynamic test condition as follows ${ }^{26}$ :

$$
N I H(g / 100 L)=\frac{\Delta H b \cdot V \cdot(100-H t) / 100}{[Q \cdot T] / 100}
$$

where $\Delta \mathrm{Hb}$ is the measured change in plasma free hemoglobin $(\mathrm{g} / \mathrm{L}), \mathrm{V}$ is the total circuit volume (L), $\mathrm{Ht}$ is the blood hematocrit $(\%), \mathrm{Q}$ is the flow rate $(\mathrm{L} / \mathrm{min})$, and $\mathrm{T}$ is the test duration $(\mathrm{min})$.

\section{In Vivo Evaluation}

Under University of Pittsburgh Institutional Animal Care and Use Committee-approved protocols at the McGowan Institute's Center for Preclinical Studies, 6 PF4 prototypes were implanted in lambs $(\mathrm{n}=11,19.0$ $30.3 \mathrm{~kg}$ ) without cardiopulmonary bypass to evaluate the chronic in vivo hemodynamic performance and biocompatibility of the PediaFlow and develop the implantable components (Table E2 in Appendix E1). Anesthesia, surgical approach, insertion, and postoperative management for the PF4 implants were similar to the 72-day PF3 implant described previously. ${ }^{22,23}$ Three sham studies, in which the aforementioned implant procedure was followed without actual device placement, were performed to serve as complementary surgical controls (Appendix E2). Blood samples were drawn at regular intervals during the course of the studies for hematology and biocompatibility assessments, including plasma-free hemoglobin, fibrinogen concentration, and platelet activation and functionality assays, followed by a complete necropsy and pump component examination. ${ }^{22,29}$ A summary of the initial PF4 implant findings and design iterations, describing the concurrent development of the inflow cannula and outflow graft, can be found in Appendix E3.

\section{Fourth-Generation PediaFlow Implantable Design}

Detailed here are the most recent PF4 implants $(n=2)$ using the de novo designed 5-mm reinforced inflow cannula featuring a parabolic-shaped inlet entrance and detachable sewing ring to unload the left ventricle (LV) (Figure 2, B) and a 6-mm Gelweave (Vascutek Ltd, Renfrewshire, Scotland, UK) outflow graft with graduated strain relief to return blood to the aorta (Figure 2, C)..$^{30}$

Surgical procedure with these implantable components varied only by first attaching the detachable sewing ring to the LV apex using pledgeted sutures after gaining access. After full anticoagulation with heparin, the outflow graft was anastomosed to the descending thoracic aorta and back-flushed before mating the graft connector to the pump outlet. The parabolic inflow cannula was inserted through the sewing ring after a cruciate incision without myocardium removal and a wet connection made to the pump inlet by the simultaneous removal of the inflow obturator and partial unclamping of the outflow graft. A perivascular ultrasonic probe (Transonic Systems, Ithaca, NY) was placed on the outflow graft to measure pump flow rate. Pump support was initiated and cannula depth optimized before thoracotomy closure. Rotational speed was adjusted as needed for a target flow rate of $1.5 \mathrm{~L} / \mathrm{min}$.

\section{RESULTS}

\section{Hemodynamic Performance In Vitro}

The characteristic performance curves of the PF4 highlighted an expanded operating range between 0.3 and $2.0 \mathrm{~L} / \mathrm{min}$ at physiologically relevant pressure ranges, a marked improvement to PF3 (Figure 3, A). Hemolysis (NIH) varied somewhat among PF4 prototypes but was very low at the 3 pediatric flow rates tested and comparable to the PediMag control (Figure 3, $B$ ). 


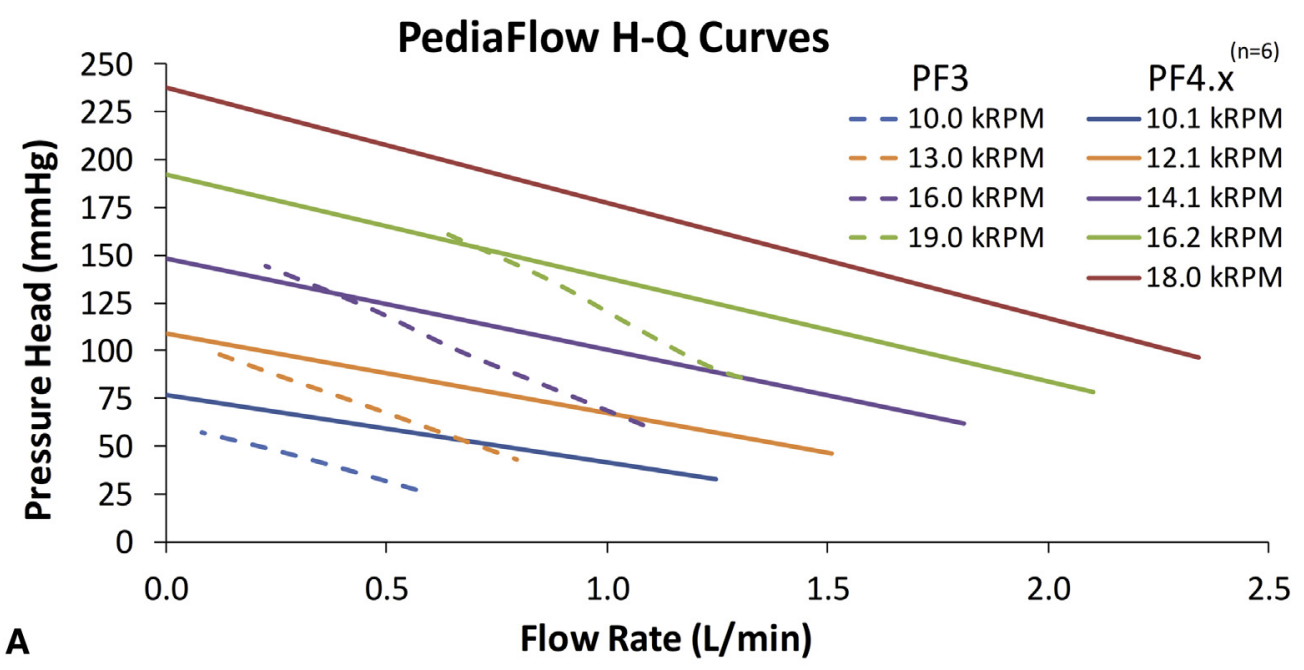

A

Flow Rate (L/min)

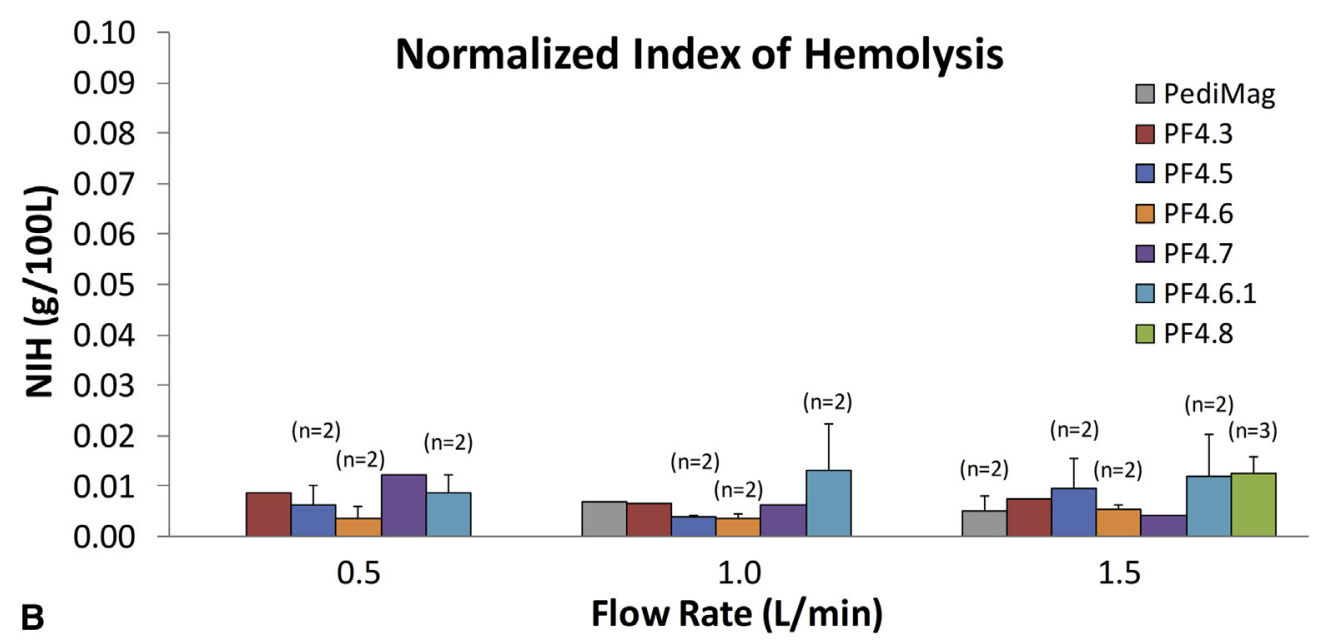

FIGURE 3. A, PF4 characteristic H-Q pump curves using a blood analog (viscosity $=2.39$ centipoise). B, The calculated in vitro NIH values (mean \pm standard deviation) for the PF4 prototypes compared with the PediMag (Thoratec, Pleasanton, Calif) control. PF3, Third-generation PediaFlow; PF4, fourth-generation PediaFlow; NIH, normalized index of hemolysis.

\section{Implantation and Operation}

The last implants with the PF4 prototypes and implantable components were unremarkable for a study duration of 14 and 60 days. Pump support was initiated within 1 hour after first incision, achieving flow rates up to 2.0 L/min before reducing motor speed (RPM) to maintain a target flow rate of $1.5 \mathrm{~L} / \mathrm{min}$ after chest closure (Figure 4, $A)$. Because of the difficulty of titrating anticoagulation for an activated clotting time target of 180 to 200 seconds during the previous PF3 study, a continuous infusion of heparin was maintained at $20 \mathrm{UI} / \mathrm{kg} / \mathrm{h}$ beginning on postoperative days 2 and 7 for PF4-S10 (60-day implant) and PF4-S11 (14-day implant), respectively (Figure 4, D).

\section{In Vivo Biocompatibility}

During the PediaFlow implants, hemodynamic performance was within the pediatric physiologic range, whereas serum chemistry, hematology, and cellular biocompatibility parameters closely followed the trends observed in the 3 surgical control sham studies (Table E3 in Appendix E1). Plasma-free hemoglobin remained within preoperative levels and fibrinogen concentration values for the implants, and surgical control animals returned to baseline by postoperative day 14 (Figure 5, $B$ and $C$ ). Platelet activation, measured by flow cytometry as percent of CD62p+ platelets, had a marked postsurgical response before returning to preoperative baseline values by postoperative day 10 . Throughout the studies, platelets remained responsive to stimulation with platelet activating factor (Figure 4, E).

\section{Necropsy}

Examination of the heart, lungs, liver, and spleen for both the PF3 and latest PF4 implants was unremarkable. The inflow cannulae were well healed within the LV apex with no myocardial injury evident, and the blood contacting surfaces of the pump, cannulae, and outflow grafts free of 

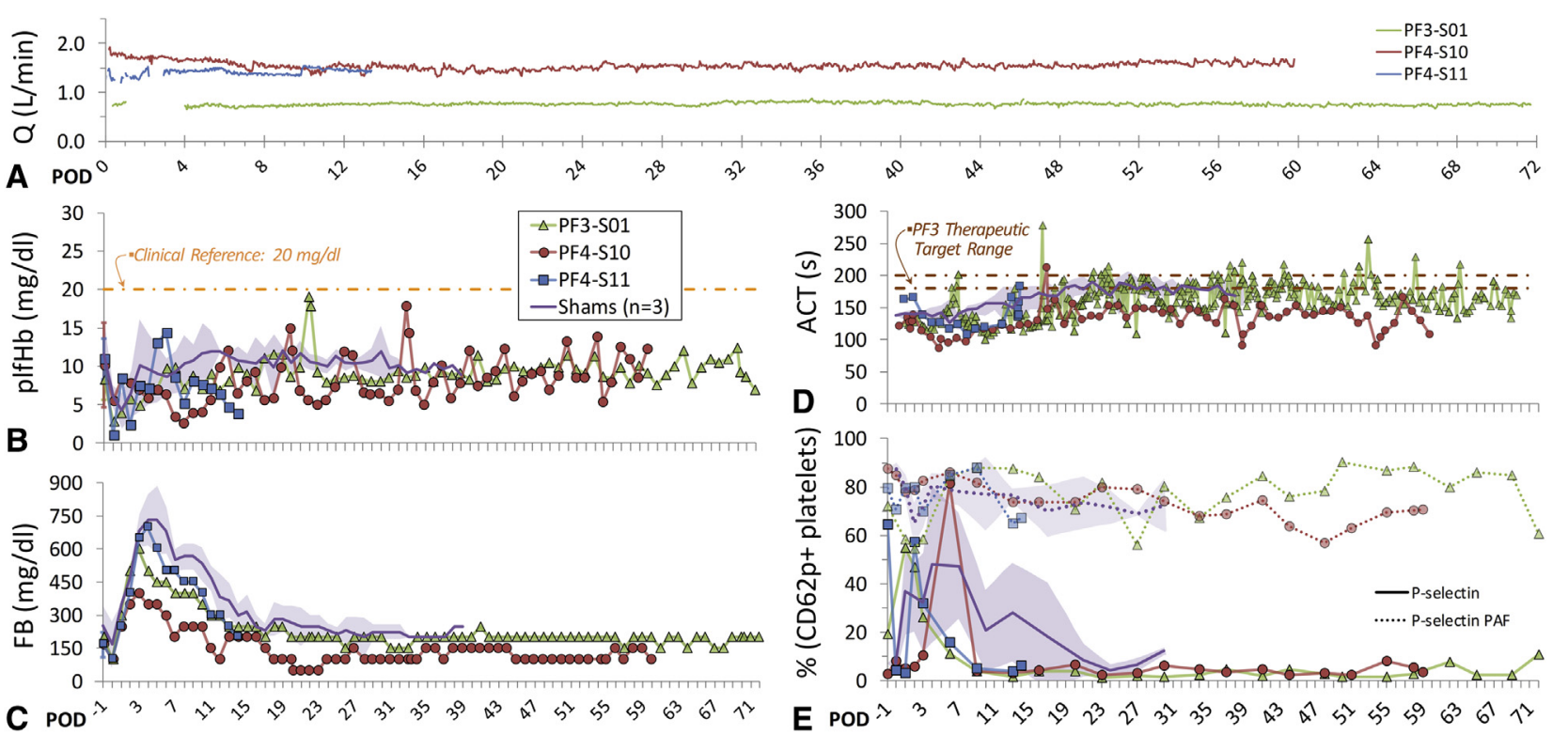

FIGURE 4. Results of the PF4 ovine studies using the current-design cannulae system (PF4-S10, PF4-S11), in comparison with the previous thirdgeneration chronic implant (PF3-S01) and the nonimplanted surgical control shams ( $\mathrm{n}=3$, mean \pm standard deviation): A, Measured pump flow rate (Q) for the implanted animals (gaps indicate durations of signal loss during postoperative acoustic recoupling of the outflow graft probe). Hematologic and hemocompatibility measurements including plasma-free hemoglobin (B), fibrinogen (C), activated clotting time (D), and platelet biocompatibility (E) as determined by the time course of platelet activation by P-selectin expression and platelet functionality by agonist stimulation using platelet activating factor. ACT, Activated clotting time; $F B$, fibrinogen; $P A F$, platelet activating factor; $P F 3$, third-generation PediaFlow; $P F 4$, fourth-generation PediaFlow; plfHb, plasma-free hemoglobin; $P O D$, postoperative day.

adherent thrombus (Figures 5-7). A well-healed, minor cortical infarction on the left kidney of the 72-day PF3 implanted animal was found, most likely from initial surgery
(Figure 5,C). No surface lesions or infarcts were found on the kidneys of the 2 PF4 implants (Figures 6, $D$ and $E$, and $7, G$ ).

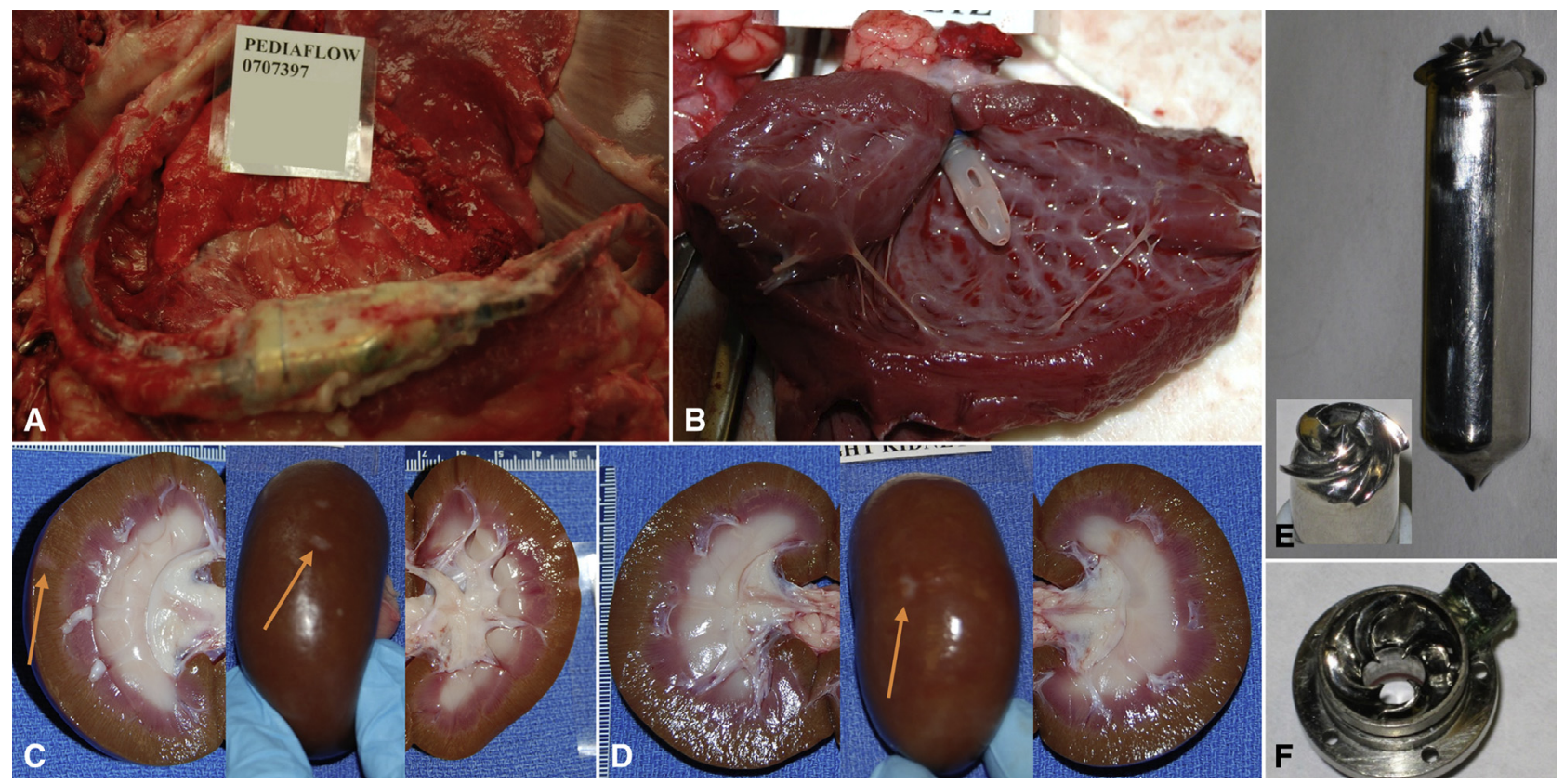

FIGURE 5. Necropsy images of the PF3-S01 (72-day) implant. A, Pump placement in situ. B, The modified 18F fenestrated inflow cannula (Medtronic DLP, Minneapolis, Minn) free of thrombus within the LV. C, Left kidney with a minor and well-healed cortical infarction. D, Right kidney with a minor surface infarction that was not visible on sagittal dissection. The pump rotor (E) and stator (F) free of deposition. 

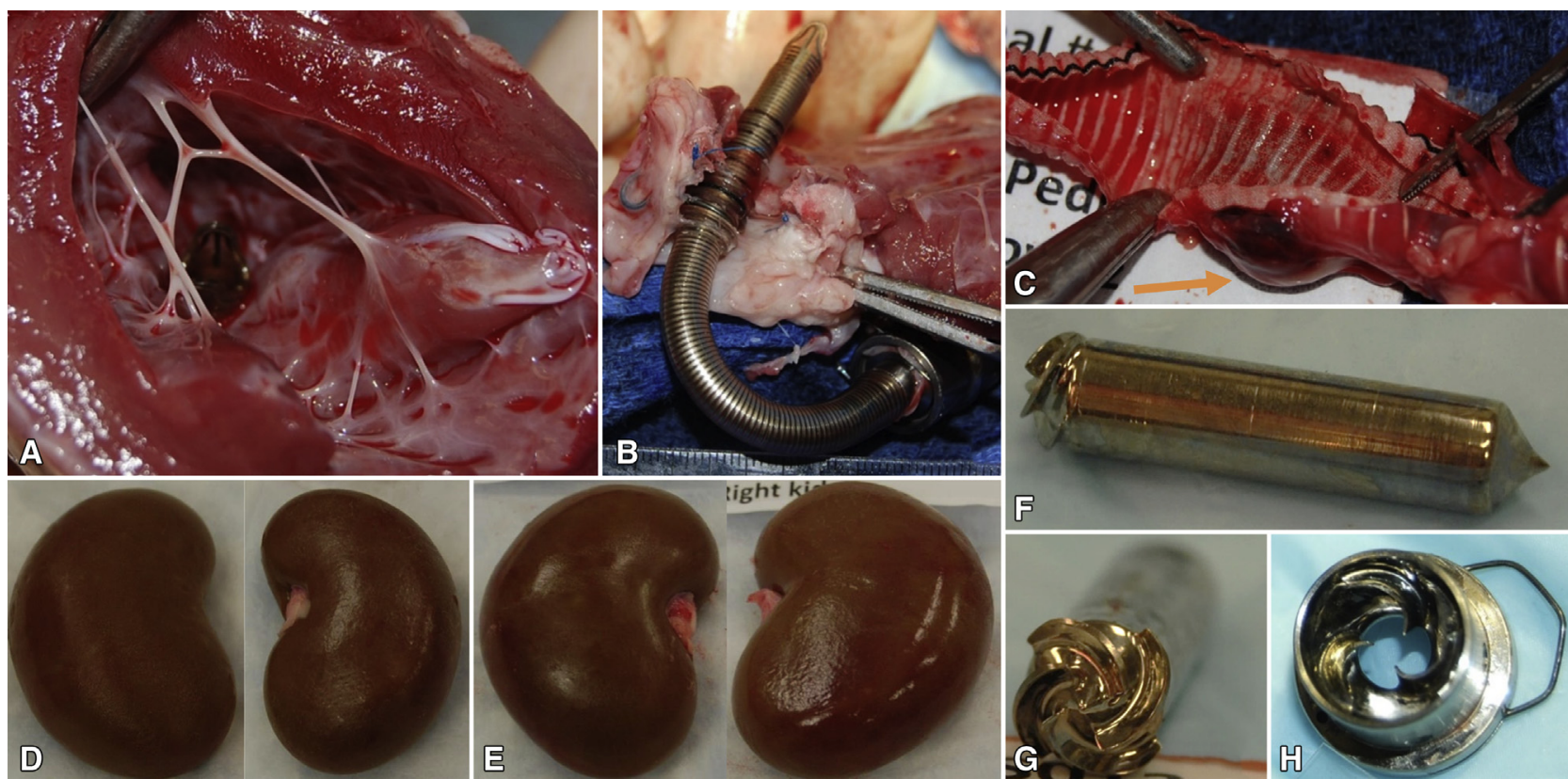

FIGURE 6. Necropsy images of PF4-S11 (14-day) implant. A, The inflow cannula position in situ. B, Cannula body free of deposition. C, Adherent thrombus on the exterior of the outflow graft, outside of the blood flow path, possibly from the de-airing needle. D and E, Kidneys without evidence of infarcts. F-H, Rotor, impeller blading, and stator free of deposition.

\section{DISCUSSION}

Implantable pediatric VADs have the potential to expand the number of children in heart failure rescued by MCS. ${ }^{31}$ The use of RBPs for the treatment of pediatric heart failure is appealing by reducing the immobilization and inpatient restrictions that are currently associated with the EXCOR. Although the successful miniaturization of CF VADs will affect pediatric MCS options, the small market size and regulatory process create a significant entry barrier for this technology in the United States. Supported by the bench and preclinical findings reported in this article, the PediaFlow has the potential to serve as a bridge-to-transplant or bridge-to-recovery device.

Consistent with the program goals for the 2 NHLBI contracts under which this work was conducted, the primary considerations for the design and development of the PediaFlow were miniaturization and reduction of serious adverse events by maximizing cellular biocompatibility, as judged
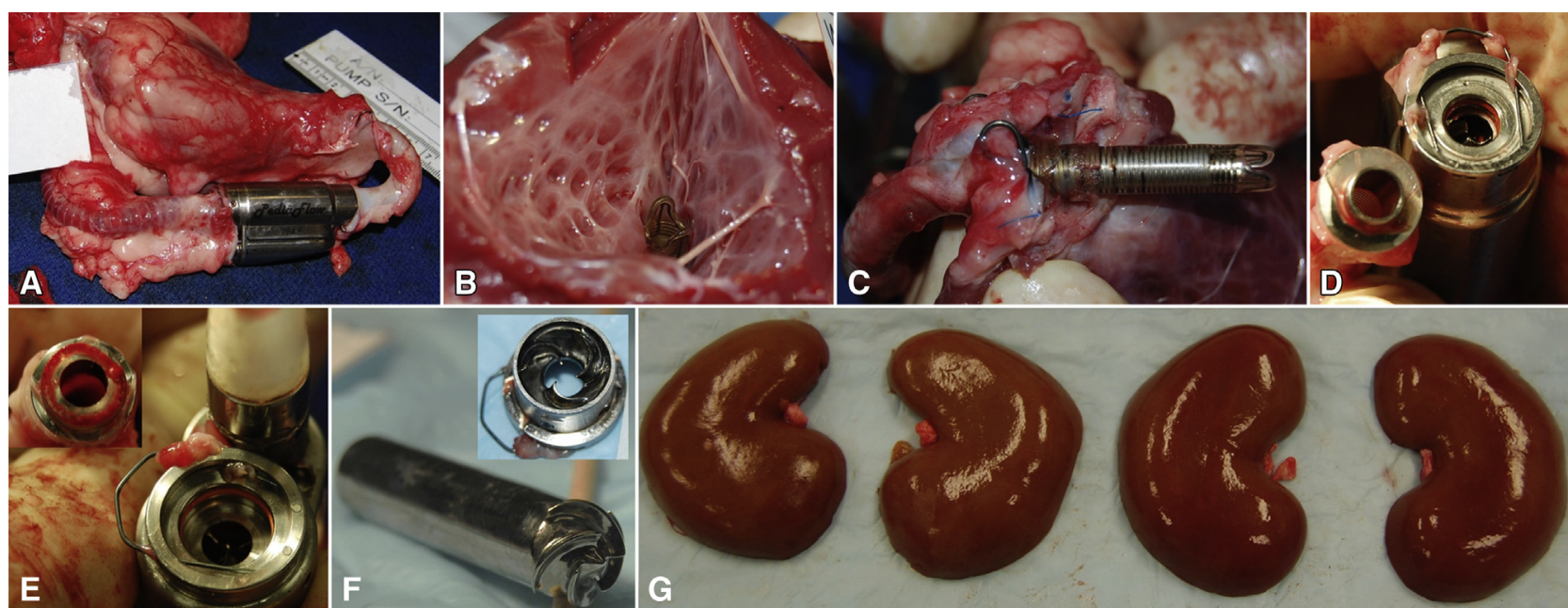

FIGURE 7. Explant photos of the PF4-S10 (60-day) implant. A, Well-encapsulated pump in situ. B, The inflow cannula tip position. C, The cannula body. Inflow (D) and outflow (E) connections free of deposition within the flow path. F, The pump rotor and stator (inset) free of deposits. G, Kidneys with no evidence of infarction. 


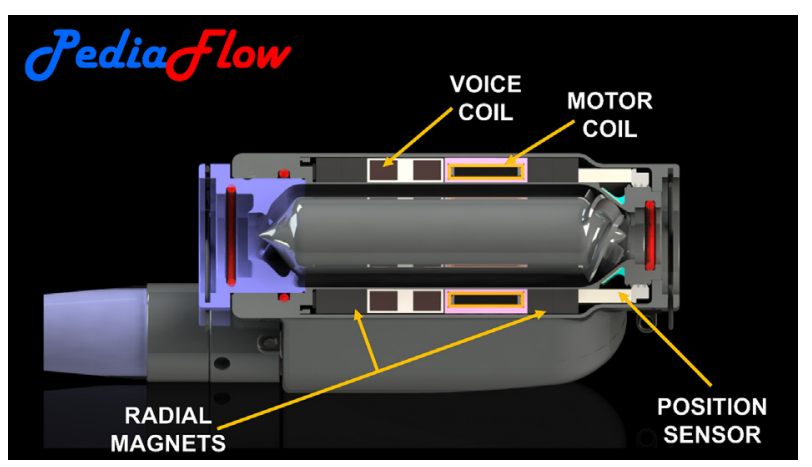

VIDEO 1. Challenges to providing chronic MCS safely in pediatric patients with heart failure and the design features of the PediaFlow pediatric VAD to address these limitations. Video available at: https://www.jtcvs. org/article/S0022-5223(18)31049-3/fulltext.

on the bench and in situ. ${ }^{23,32,33}$ In silico optimization of the rotodynamics, magnetodynamics, heat transfer, and fluid dynamics yielded 4 successively smaller prototypes that were built and tested both in vitro and in vivo. Figure 1 displays the marked reduction in profile of the PediaFlow design in successive generations of prototypes (PF1-PF4), with the PF4 prototype approximating the size of an AA cell battery (Figure 2, A). By increasing the voice (levitation) coil to motor stator size-ratio to enhance rotor stability and optimizing the pump blading from PF3, flow rates were improved enabling PF4 to reach the target design goals. With an NIH of less than $0.02 \mathrm{~g} / 100 \mathrm{~L}$ for the final PF4 prototypes, the PediaFlow PF4 device is nonhemolytic (eg, the NIH for the PF4 approximates that of the maglev PediMag) and less than published literature values for both adult and pediatric devices. ${ }^{26,34,35}$ We attribute the absence of hemolysis to the fully magnetically levitated rotor design, the optimized single blood flow path, and the relatively large annular gap $(1.5 \mathrm{~mm})$, which eliminates the need for bearings or seals, thereby reducing hemolytic potential. Because each PF4 pump was hand-built, the variation in NIH among prototypes is likely due to assembly and polishing tolerances.

Another design consideration for the PediaFlow technology is that pediatric MCS should be rapidly deployable and customizable to support the representative patient population. The use of cardiopulmonary bypass for VAD implantation is expected; however, limiting on-pump time remains ideal. Within this context, and for the PediaFlow inflow cannula, the removable sewing ring provides accurate and unencumbered placement onto the heart apex before allowing insertion and tool-less securement of the inflow body within the LV. The reinforced parabolic-shaped inflow tip (Figure 2, B) eases insertion and serves as a clinical marker for echocardiography perioperatively to adjust insertion depth and postoperatively when assessing cannula position. Along with the preassembled outflow graft and quick connect mechanisms (Figure 2, C), pump support was initiated in the latest studies in less than 1 hour from first incision without the use of cardiopulmonary bypass. Without any evidence of ventricular suction supported by explant analysis in the PF3 and PF4 implant studies, we hypothesize that the additional flow paths provided by the inlet shape geometry render the parabolic tip resistant to entrapment and less sensitive to positional variations. ${ }^{30}$

Although in vivo analysis is performed in healthy animals and does not necessarily reflect the causes in children (ie, congenital, dilated, or restrictive cardiomyopathies), the results are nonetheless encouraging. The biocompatibility findings in vivo (Figure 5) and explant analyses (Figures 6 and 7) are consistent with the in vitro results demonstrating no hemolysis, platelet activation, or platelet dysfunction during implant periods up to 2 months. The lack of documented renal insufficiency or other evidence of thrombogenesis or thromboembolic events with only relatively low-dose heparin and subtherapeutic activated clotting times is especially promising toward the design goal for the PediaFlow pediatric VAD of solely antiplatelet therapies to minimize bleeding risk clinically. ${ }^{32,33}$ Additional implants using the current PF4 design and components are necessary to demonstrate reproducibility of the preclinical assessment for Investigation Device Exemption application.

\section{CONCLUSIONS}

This report is the culmination of 10 years of NHLBIsupported development of a miniaturized, implantable RBP for the chronic support of infants/small children with congenital or acquired cardiac defects (Video 1). More than 20 design variations were evaluated and judged on the basis of a multicomponent objective function that factored several criteria, including anatomic fit, cellular biocompatibility, heat generation and transfer, magnetically levitated suspension robustness, and manufacturability. ${ }^{23}$ The design was improved and miniaturized through successive pump prototypes using computational fluid dynamics to minimize flow-induced blood damage via modification of the geometry of the predicted blood flow path. ${ }^{24}$ The pump housing was modified to improve surgical fixation and the inflow/outflow attachments optimized to permit ease of insertion according to human factors engineering principles.

The data presented document the exceptional biocompatibility and the potential of safely providing chronic MCS to neonates and infants using a miniature, implantable, magnetically levitated, rotodynamic blood pump. Per the requirements of the NHLBI contract programs, the PediaFlow has been designated by the FDA as a Humanitarian Use Device for "mechanical circulatory support in neonates, infants, and toddlers weighing up to $20 \mathrm{~kg}$ as a bridge to transplant, a bridge to other therapeutic intervention such as surgery, or a bridge to recovery." This important designation provides insight as to the remaining preclinical testing (both on the bench and in vivo) to be undertaken. Although accurate flow estimation 
has been achieved (Figure E1 in Appendix E1), work remains, including the final prototyping and testing of a clinical-use controller, which is required for the final preclinical studies in anticipation of submitting an Investigational Device Exemption application to the FDA.

\section{Conflict of Interest Statement}

The University of Pittsburgh, Carnegie Mellon University, and LaunchPoint Technologies, LLC, are co-inventors of the PediaFlow technology. The PediaFlow IP is licensed to HeartWare International, Inc (Framingham, Mass). Authors have nothing to disclose with regard to commercial support.

The authors thank all of the members of the PediaFlow Consortium who participated in and contributed to the development of the PediaFlow pediatric VAD, including but not limited to Dr Gil Bearnson, Shawn Bengston, Dr Amanda Daly, Teri Dulak, Dr Antonio Ferreira, Joseph Hanke, Jal Jassawalla, Dr Carl Johnson, Dr Bradley Keller, Dr Pratap Khanwilkar, Dr Jeongho Kim, Phil Miller, Dr Brad Paden, Dave Paden, Michael Ricci, Dr Richard Schaub, Dr Fangjun Shu, Dr Trevor Snyder, Dr Dennis Trumble, Josiah Verkaik, Dr Stijn Vandenberghe, Andrew Wearden, Dr Steven Webber, Steven Winowich, Dr Joshua Woolley, and $\mathrm{Dr}$ Jingchun Wu. The PediaFlow is the culmination of work from our consortium beginning with the StreamLiner VAD, which was the world's first magnetically levitated axial/mixed flow VAD.

\section{References}

1. Mozaffarian D, Benjamin EJ, Go AS, Arnett DK, Blaha MJ, Cushman M, et al. Heart Disease and Stroke Statistics-2015 Update: a report from the American Heart Association. Circulation. 2015;131:e29-322.

2. Garatti A, Bruschi G, Colombo T, Russo C, Lanfranconi M, Milazzo F, et al. Clinical outcome and bridge to transplant rate of left ventricular assist device recipient patients: comparison between continuous-flow and pulsatile-flow devices. Eur J Cardiothorac Surg. 2008;34:276-80.

3. Lahpor JR. State of the art: implantable ventricular assist devices. Curr Opin Organ Transplant. 2009;14:554-9.

4. Slaughter MS, Rogers JG, Milano CA, Russell SD, Conte JV, Feldman D, et al. Advanced heart failure treated with continuous-flow left ventricular assist device. N Engl J Med. 2009;361:2241-51.

5. Clegg AJ, Scott DA, Loveman E, Colquitt J, Royle P, Bryant J. Clinical and costeffectiveness of left ventricular assist devices as destination therapy for people with end-stage heart failure: a systematic review and economic evaluation. Int J Technol Assess Health Care. 2007;23:261-8.

6. American Heart Association. 2005 Statistical Reference Book. Dallas, TX: American Heart Association; 2005

7. Lipshultz SE, Sleeper LA, Towbin JA, Lowe AM, Orav EJ, Cox GF, et al. The incidence of pediatric cardiomyopathy in two regions of the United States. N Engl J Med. 2003;1647-55.

8. Boneva RS, Botto LD, Moore CA, Yang Q, Correa A, Erickson JD. Mortality associated with congenital heart defects in the United States: trends and racial disparities, 1979-1997. Circulation. 2001;2376-81.

9. Almond CS, Thiagarajan RR, Piercey GE, Gauvreau K, Blume ED, Bastardi HJ, et al. Waiting list mortality among children listed for heart transplantation in the United States. Circulation. 2009;717-27.

10. Organ Procurement and Transplantation Network. Vol 2015: US Department of Health \& Human Services. Available at: https://optn.transplant.hrsa.gov. Accessed September 11, 2015.

11. Baldwin JT, Borovetz HS, Duncan BW, Gartner MJ, Jarvik RK, Weiss WJ, et al. The national heart, lung, and blood institute pediatric circulatory support program. Circulation. 2006;113:147-55.

12. Goldman AP, Cassidy J, de Leval M, Haynes S, Brown K, Whitmore P, et al. The waiting game: bridging to paediatric heart transplantation. Lancet. 2003;1967-70.
13. Deiwick M, Hoffmeier A, Tjan TD. Heart failure in children: mechanical assistance. Thorac Cardiovasc Surg. 2005;S135-40.

14. Kulik TJ, Moler FW, Palmisano JM. Outcome-associated factors in pediatric patients treated with extracorporeal membrane oxygenator after cardiac surgery Circulation. 1996;1163-8.

15. Kirklin JK, Naftel DC, Pagani FD, Kormos RL, Stevenson LW, Blume ED, et al. Seventh INTERMACS annual report: 15,000 patients and counting. $J$ Heart Lung Transplant. 2015;34:1495-504.

16. Honjo O, Rao V. Implantation of HeartWare left ventricular assist device in pediatric population. Oper Tech Thorac Cardiovasc Surg. 2014;19:80-95.

17. VanderPluym CJ, Fynn-Thompson F, Blume ED. Ventricular assist devices in children: progress with an orphan device application. Circulation. 2014;129: $1530-7$.

18. Sharma MS, Webber SA, Morell VO, Gandhi SK, Wearden PD, Buchanan JR, et al. Ventricular assist device support in children and adolescents as a bridge to heart transplantation. Ann Thorac Surg. 2006;82:926-32.

19. Fraser CD Jr, Jaquiss RDB, Rosenthal DN, Humpl T, Canter CE, Blackstone EH, et al. Prospective trail of a pediatric ventricular assist device. N Engl J Med. 2012; 367:532-41.

20. Baldwin JT, Borovetz HS, Duncan BW, Gartner MJ, Jarvik RK, Weiss WJ. The national heart, lung, and blood institute pediatric circulatory support program. A summary of the 5-year experience. Circulation. 2011;1233-40.

21. Uber BE, Webber SA, Morell VO, Antaki JF. Hemodynamic guidelines for design and control of a turbodynamic pediatric ventricular assist device. ASAIO J. 2006;52:471-8.

22. Maul TM, Kocyildirim E, Johnson CA Jr, Daly AR, Olia SE, Woolley JR, et al In vitro and in vivo performance evaluation of the second developmental version of the PediaFlow pediatric ventricular assist device. Cardiovasc Eng Technol. 2011;2:253-62.

23. Antaki JF, Ricci MR, Verkaik JE, Snyder ST, Maul TM, Kim J, et al. PediaFlow Maglev ventricular assist device: a prescriptive design approach. Cardiovasc Eng. 2010;1:104-21.

24. Wu J, Antaki JF, Verkaik J, Snyder S, Ricci M. Computation fluid dynamicsbased design optimization for an implantable miniature maglev pediatric ventricular assist device. J Fluids Eng. 2012;134:041101-9.

25. F1841-97 AS. Standard Practice for Assessment of Hemolysis in Continuous Flow Blood Pumps. West Conshohocken, PA: ASTM International; 2013.

26. Naito K, Mizuguchi K, Nose Y. The need for standardizing the index of hemolysis. Artif Organs. 1994;7-10.

27. Maul TM, Kameneva MV, Wearden PD. Mechanical Blood Trauma in Circulatory-Assist Devices. New York: ASME Press: Momentum Press; 2015.

28. Herbertson LH, Olia SE, Daly AR, Noatch CP, Smith WA, Kameneva MV, et al Multi-laboratory study of flow-induced hemolysis using the FDA benchmark nozzle model. Artif Organs. 2015;39:237-48.

29. Johnson CA, Wearden PD, Kocyildirim E, Maul TM, Woolley JR, Ye SH, et al. Platelet activation in ovines undergoing sham surgery or implant of the second generation PediaFlow pediatric ventricular assist device. Artif Organs. 2011; 35:602-13.

30. Griffin MT, Grzywinski MF, Voorhees HJ, Kameneva MV, Olia SE. Ex vivo assessment of a parabolic-tip inflow cannula for pediatric continuous-flow VADs. Asaio J. 2016;62:600-6.

31. Webber S. Pediatric circulatory support contractors' meeting: report of the clinical trials working group. ASAIO J. 2009;55:10-2.

32. Borovetz HS, Badylak SF, Boston JR, Johnson CA, Kormos RL, Kameneva MV et al. Towards the development of a pediatric ventricular assist device. Cell Transplant. 2006;15:S69-74.

33. Wearden PD, Morell VO, Keller BB, Webber SA, Borovetz HS, Badylak SF, et al The PediaFlow pediatric ventricular assist device. Semin Thorac Cardiovasc Surg Pediatr Card Surg Annu. 2006;9:92-8.

34. Giridharan GA, Sobieski MA, Ising M, Slaughter MS, Koenig SC. Blood trauma testing for mechanical circulatory support devices. Biomed Instrum Technol. 2011:45:334-9.

35. Baldwin JT, Adachi I, Teal J, Almond CA, Jaquiss RD, Massicotte MP, et al. Closing in on the PumpKIN Trial of the Jarvik 2015 ventricular assist device. Semin Thorac Cardiovasc Surg Pediatr Card Surg Annu. 2017;20:9-15.

Key Words: pediatric heart failure, congenital heart disease, continuous flow, blood pump, hemocompatibility, biocompatibility 


\section{APPENDIX E1}

TABLE E1. Summary of the fourth-generation PediaFlow prototypes fabricated by the Consortium

\begin{tabular}{|c|c|c|c|}
\hline Prototype & Extent of testing & Modifications & Manufacturing findings \\
\hline PF4.1 & Nonoperational & - & - \\
\hline PF4.2 & In vitro & $\begin{array}{l}\text { Epoxy-sealed feed-through assembly and printed } \\
\text { circuit board }\end{array}$ & $\begin{array}{l}\text { Ground failure at feed-through requiring external } \\
\text { grounding precluding in vivo assessment }\end{array}$ \\
\hline PF4.3 & In vivo & $\begin{array}{l}\text { Improved percutaneous cable feed-through } \\
\text { attachment design }\end{array}$ & - \\
\hline PF4.4 & Nonoperational & - & Noncompliant components \\
\hline PF4.5 & In vivo & - & - \\
\hline PF4.6 & In vivo & - & - \\
\hline PF4.7 & In vivo & $\begin{array}{l}\text { Revised stator housing to accommodate a Gelweave- } \\
\text { compatible (Vascutek Ltd, Renfrewshire, } \\
\text { Scotland, United Kingdom) outflow assembly } \\
\text { connection }\end{array}$ & $\begin{array}{l}\text { Epoxy infiltration into driveline during hermetic } \\
\text { sealing leading to eventual fracture from fatigue }\end{array}$ \\
\hline PF4.6.1* & In vivo & $\begin{array}{l}\text { 1. Reduced-size driveline connector } \\
\text { 2. Smoothing filter on motor current signal }\end{array}$ & - \\
\hline PF4.8* & In vivo & $\begin{array}{l}\text { (refurbished PF4.7) } \\
\text { Copper-shielded percutaneous cable }\end{array}$ & - \\
\hline
\end{tabular}

A total of 9 PF4 prototypes were fabricated, with 6 builds remitted for in vivo implantation and biocompatibility testing. Aside from variations due to manufacturing tolerances, the pump topologies (ie, blood flow paths) are identical across the PF4 generation. Instead, each hand-built pump represents the incorporation of incremental improvements based on fabrication or implant findings of the previous prototype. PF4, Fourth-generation PediaFlow. *Used in the 60- and 14-day implants presented in the main text. 
TABLE E2. Experimental details and relevant results of all fourth-generation PediaFlow ovine implants $(\mathbf{n}=11)$ performed to develop, assess, and refine the implantable peripherals in addition to evaluating device hemodynamics and biocompatibility

\begin{tabular}{|c|c|c|c|c|c|c|}
\hline Study implant & Weight (kg) & Pump & $\begin{array}{l}\text { Inflow cannula: } \\
\text { Outflow assembly: }\end{array}$ & $\begin{array}{c}\text { Time (d) } \\
\text { Intended/actual }\end{array}$ & $\begin{array}{l}\text { Average flow } \\
\text { (L/min) }\end{array}$ & Pertinent findings \\
\hline PF4-S01 & 28.0 & PF4.3 & $\begin{array}{l}\text { I: } 22 \mathrm{~F} \text { Fenestrated } \\
\text { O: Bard ePTFE }\end{array}$ & $4 / 14$ & 1.2 & $\begin{array}{l}\text { 1. Serosanguinous fluid collection } \\
\text { 2. Constricted outflow anastomosis }\end{array}$ \\
\hline PF4-S02 & 27.9 & PF4.3 & $\begin{array}{l}\text { I: } 22 \mathrm{~F} \text { Fenestrated } \\
\text { O: Bard ePTFE }\end{array}$ & $15 / 28$ & 0.9 & $\begin{array}{l}\text { 1. Detached pump inlet connection } \\
\text { 2. Fibrous deposition surrounding } \\
\text { outflow graft along entire length } \\
\text { 3. Graft kink at pump attachment }\end{array}$ \\
\hline PF4-S03 & 23.0 & PF4.5 & $\begin{array}{l}\text { I: Bevel } 1.0 \\
\text { O: Bard ePTFE }\end{array}$ & $<1$ & N/A & $\begin{array}{l}\text { 1. Respiratory failure perioperatively } \\
\text { after chest closure } \\
\text { 2. Nonseated outflow connector }\end{array}$ \\
\hline PF4-S04 & 24.5 & PF4.5 & $\begin{array}{l}\text { I: Bevel } 1.1 \\
\text { O: SEAL-PTFE }\end{array}$ & $4 / 28$ & 1.5 & $\begin{array}{l}\text { 1. Respiratory failure secondary to } \\
\text { thoracic blood collection } \\
\text { 2. Outflow graft thrombus }\end{array}$ \\
\hline PF4-S05 & 28.0 & PF4.6 & $\begin{array}{l}\text { I: Bevel } 1.1 \\
\text { O: SEAL-PTFE }\end{array}$ & $4 / 28$ & 1.0 & $\begin{array}{l}\text { 1. Cardiac compression secondary to } \\
\text { large thoracic hematoma } \\
\text { 2. Tissue entrapped on cannula tip } \\
\text { 3. Thrombus present at base of LV }\end{array}$ \\
\hline PF4-S06 & 22.3 & PF4.7 & $\begin{array}{l}\text { I: Bevel } 1.1 \\
\text { O: Gelweave }\end{array}$ & $28 / 28$ & 1.3 & 1. Inflow cannula kink \\
\hline PF4-S07 & 27.3 & PF4.7 & $\begin{array}{l}\text { I: Bevel } 1.1 \\
\text { O: Gelweave }\end{array}$ & $12 / 28$ & 1.5 & $\begin{array}{l}\text { 1. Rotor position sensor failure } \\
\text { secondary to driveline fracture } \\
\text { 2. Inflow cannula kink }\end{array}$ \\
\hline PF4-S08 & 28.2 & PF4.6.1 & $\begin{array}{l}\text { I: Bevel } 2.0 \\
\text { O: Gelweave }\end{array}$ & $9 / 28$ & 2.0 & $\begin{array}{l}\text { 1. Tamponade secondary to infectious } \\
\text { pericarditis } \\
\text { 2. Large thoracic hematoma }\end{array}$ \\
\hline PF4-S09 & 19.0 & PF4.8 & $\begin{array}{l}\text { I: Bevel } 2.0 \\
\text { O: Gelweave }\end{array}$ & $15 / 28$ & 1.0 & $\begin{array}{l}\text { 1. Cardiovascular collapse } \\
\text { 2. Thoracic hematoma } \\
\text { 3. Inflow cannula kink }\end{array}$ \\
\hline PF4-S10* & 28.7 & PF4.6.1 & $\begin{array}{l}\text { I: Parabolic } \\
\text { O: Gelweave }\end{array}$ & $60 / 60$ & 1.6 & 1. Unremarkable \\
\hline PF4-S11*,† & 30.3 & PF4.8 & $\begin{array}{l}\text { I: Parabolic } \\
\text { O: Gelweave }\end{array}$ & $14 / 28$ & 1.4 & $\begin{array}{l}\text { 1. Hemodynamic and } \\
\text { biocompatibility design goals } \\
\text { achieved until de-levitation due to } \\
\text { wear from repeated refurbishments }\end{array}$ \\
\hline
\end{tabular}

Bard ePTFE is a product of Bard Peripheral Vascular (Tempe, Ariz). SEAL-PTFE, and Gelweave are products of Vascutek Ltd (Renfrewshire, Scotland, UK). PF4, Fourth-generation PediaFlow; ePTFE, expanded polytetrafluoroethylene; $N A$, not available; $L V$, left ventricle. *The most recent implants presented in the main text using the parabolic-inflow cannula and Gelweave-based outflow graft assembly. $\nmid$ Although initially implanted for an intended 30-day study, the study was electively terminated on postoperative day 14 because of irrecoverable de-levitation of the rotor. Although each PediaFlow prototype is indicated for single-use, the PF4 pump (PF4.8) implanted in PF4-S11 had been implanted and refurbished multiple times previously, leading to excessive wear, a failure mode that would not be expected clinically. 
TABLE E3. Additional blood parameters of the third- and fourth-generation PediaFlow and sham in vivo animal studies presented in the main article: All were within reference values

\begin{tabular}{|c|c|c|c|c|c|}
\hline & PF3-S01 (72 d) & PF4-S10 (14 d) & PF4-S11 (60 d) & Sham implants $(n=3$, mean) & Reference range \\
\hline Weight (kg) & (24) & $(30)$ & $(28.7)$ & $(43.3 \pm 12.7)$ & \\
\hline WBC $\left(\times 10^{3} / \mathrm{mm}^{3}\right)$ & $7.3 \pm 1.2(7.2)$ & $8.6 \pm 2.8(9.5)$ & $13.4 \pm 3.4(12.8)$ & $5.0 \pm 0.5(5.6)$ & $4-12$ \\
\hline $\mathrm{RBC}\left(\times 10^{6} / \mathrm{mm}^{3}\right)$ & $7.6 \pm 0.5(10.3)$ & $8.2 \pm 0.7(13.1)$ & $10.0 \pm 0.7(13.4)$ & $8.5 \pm 0.7(9.9)$ & $9-15$ \\
\hline $\mathrm{Hgb}(\mathrm{g} / \mathrm{dL})$ & $8 \pm 0.9(9.9)$ & $7.7 \pm 0.6(12.3)$ & $10.7 \pm 0.7(14.2)$ & $9.6 \pm 1.0(10.0)$ & $9-15$ \\
\hline $\operatorname{HCT}(\%)$ & $23.3 \pm 2.7(26.5)$ & $24.1 \pm 1.3(37.6)$ & $31.9 \pm 1.9(41.5)$ & $26.6 \pm 2.2(31.9)$ & $27-45$ \\
\hline Platelets $\left(\times 10^{3} / \mathrm{mm}^{3}\right)$ & $626 \pm 248(2000)$ & $855 \pm 477(634)$ & $605 \pm 306(518)$ & $755 \pm 571(1406)$ & $250-750$ \\
\hline $\operatorname{MCV}\left(\mu \mathrm{m}^{3}\right)$ & $29.7 \pm 1.8(26)$ & $29.7 \pm 1.5(29)$ & $31.9 \pm 1.0(31)$ & $31.4 \pm 2.3(31)$ & $28-40$ \\
\hline $\mathrm{MCH}(\mathrm{pg})$ & $10.3 \pm 0.6(9.6)$ & $9.4 \pm 0.3(9.4)$ & $10.7 \pm 0.3(10.7)$ & $11.4 \pm 0.3(10.2)$ & $8-12$ \\
\hline $\mathrm{MCHC}(\%)$ & $34.9 \pm 1.2(37.4)$ & $31.8 \pm 1.3(32.7)$ & $33.7 \pm 0.9(34.4)$ & $35.8 \pm 4.6(35.2)$ & $31-34$ \\
\hline Neutrophils $\left(\times 10^{3} / \mathrm{mm}^{3}\right)$ & $3 \pm 1.3(1.7)$ & $3.8 \pm 1.7(3.2)$ & $3.7 \pm 2.4(4.3)$ & $2.2 \pm 0.5(1.9)$ & $0.7-6.0$ \\
\hline Lymphocytes $\left(\times 10^{3} / \mathrm{mm}^{3}\right)$ & $3.7 \pm 1.5(4.6)$ & $4.5 \pm 2.1(6.2)$ & $9.2 \pm 2.4(8.2)$ & $2.4 \pm 0.5(3.2)$ & $2-9$ \\
\hline $\mathrm{PT}(\mathrm{s})$ & $22.1 \pm 6.2(26.6)$ & $16.5 \pm 7.3(15.2)$ & $16.9 \pm 2.2(16.2)$ & $17.1 \pm 3.4(20.0)$ & N/A \\
\hline INR & $2.2 \pm 3.5(2.3)$ & N/A & N/A & N/A & N/A \\
\hline PTT (s) & $61.2 \pm 22.7$ & $43.7 \pm 8.2(44.5)$ & $49.4 \pm 12.8(33.9)$ & $31.1 \pm 7.7(38.2)$ & N/A \\
\hline BUN (mg/dL) & $21 \pm 15.3(16)$ & $16 \pm 5.4(12)$ & $11.2 \pm 2.7(13)$ & $14.3 \pm 1.9(16)$ & $10.3-26$ \\
\hline Glucose (mg/dL) & $91.9 \pm 15.1(88)$ & $96.5 \pm 32.1(74)$ & $77.9 \pm 7.1(86.5)$ & $75.2 \pm 4.3(77.3)$ & $44-81.2$ \\
\hline Creatinine (mg/dL) & $1.4 \pm 1.5(0.8)$ & $0.9 \pm 0.3(0.7)$ & $0.6 \pm 0.1(0.5)$ & $1.3 \pm 1.1(0.6)$ & $0.9-2.0$ \\
\hline $\mathrm{Ca}(\mathrm{mg} / \mathrm{dL})$ & $10 \pm 0.9(10.5)$ & $8.8 \pm 1.1(10.8)$ & $10.1 \pm 0.9(10.9)$ & $9.9 \pm 0.3(10.2)$ & $9.3-11.7$ \\
\hline $\mathrm{Mg}(\mathrm{mEQ} / \mathrm{L})$ & $1.1 \pm 0.2(1.6)$ & $1.4 \pm 0.3(1.5)$ & $1.6 \pm 0.2(1.8)$ & $1.6 \pm 0.0(1.6)$ & $2.0-2.7$ \\
\hline $\mathrm{Cl}(\mathrm{mmol} / \mathrm{L})$ & $111 \pm 4.7(105)$ & $109 \pm 5.5(107)$ & $109 \pm 3.3(110)$ & $109 \pm 2.7(108)$ & $100.8-113.0$ \\
\hline $\mathrm{K}(\mathrm{mmol} / \mathrm{L})$ & $6.1 \pm 1.6(4.4)$ & $4.3 \pm 0.7(5.2)$ & $5.2 \pm 0.6(4.7)$ & $5.5 \pm 0.8(4.3)$ & $4.3-6.3$ \\
\hline $\mathrm{Na}(\mathrm{mmol} / \mathrm{L})$ & $143 \pm 4(144)$ & $144 \pm 3.3(144)$ & $145 \pm 3.5(150)$ & $144 \pm 0.5$ & $141.6-159.6$ \\
\hline SGPT(ALT) (IU/L) & $11 \pm 9(13)$ & $12.3 \pm 10.5(9)$ & $10.4 \pm 8.6(10.5)$ & $21.0 \pm 17.6(27.8)$ & $14.8-43.8$ \\
\hline SGOT(AST) (IU/L) & $76 \pm 46(71)$ & $212 \pm 127(82)$ & $99 \pm 67(78)$ & $71 \pm 30(70)$ & $49.0-123.0$ \\
\hline Albumin (g/dL) & $2.7 \pm 0.6(3)$ & $2.2 \pm 0.3(3.2)$ & $2.8 \pm 0.5(3.4)$ & $2.9 \pm 0.1(2.9)$ & $2.4-3.0$ \\
\hline Total bilirubin (mg/dL) & $0.1 \pm 0(0.2)$ & $0.1 \pm 0.1(0.1)$ & $0.6 \pm 1.6(0.1)$ & $0.3 \pm 0.2(0.2)$ & $0.1-0.5$ \\
\hline GGT (IU/L) & $44 \pm 13(57)$ & $36.4 \pm 6.0(54)$ & $36 \pm 3.6(52)$ & $67 \pm 25(73)$ & $10-118$ \\
\hline LDH (IU/L) & $437 \pm 146(325)$ & $713 \pm 355(383)$ & $427 \pm 115(439)$ & $377 \pm 8(365)$ & $238-560$ \\
\hline Phosphorus (mg/dL) & $8.1 \pm 1(7.5)$ & $5.1 \pm 2.0(6.2)$ & $7.8 \pm 1.3(6.4)$ & $7.2 \pm 1.1(6.4)$ & $4.0-7.3$ \\
\hline Cholesterol (mg/dL) & $71.1 \pm 26(40)$ & $47.8 \pm 26.2(56)$ & $48.9 \pm 13.8(33.5)$ & $71.7 \pm 19.3$ & $44.1-90.1$ \\
\hline ALP (IU/L) & $82.7 \pm 23.6(139)$ & $100.8 \pm 26.2(144)$ & $92.8 \pm 17.7(195.5)$ & $112.3 \pm 47.1(230)$ & $26.9-156.1$ \\
\hline CPK (IU/L) & $500 \pm 1181(111)$ & $642 \pm 805(145)$ & $613 \pm 1678(128)$ & $270.8 \pm 147.4(300)$ & $47-4212$ \\
\hline Total protein $(\mathrm{g} / \mathrm{dL})$ & $5.2 \pm 0.4(5.7)$ & $4.0 \pm 0.5(5.5)$ & $5.1 \pm 0.7(5.7)$ & $5.3 \pm 0.2(5.6)$ & $5.9-7.8$ \\
\hline
\end{tabular}

Data presented as mean \pm standard deviation (preoperative mean). $P F 3$, Third-generation PediaFlow; $P F 4$, fourth-generation PediaFlow; $W B C$, white blood cell; $R B C$, red blood cell; $H g b$, hemoglobin; $H C T$, hematocrit; $M C V$, mean corpuscular volume; $M C H$, mean corpuscular hemoglobin; $M C H C$, mean corpuscular hemoglobin concentration; $P T$, prothrombin time; $N / A$, not available; $I N R$, international normalized ratio; $P T T$, partial prothrombin time; $B U N$, blood urea nitrogen; $C a$, calcium; $M g$, magnesium; $C l$, chlorine; $K$, potassium; $N a$, sodium; $S G P T$, serum glutamic pyruvic transaminase; $A L T$, alanine transaminase; $S G O T$, serum glutamic oxaloacetic transaminase; $A S T$, aspartate transaminase; $G G T$, gamma-glutamyltransferase; $L D H$, lactate dehydrogenase; $A L P$, Alkaline phosphatase; $C P K$, creatine phosphokinase. 


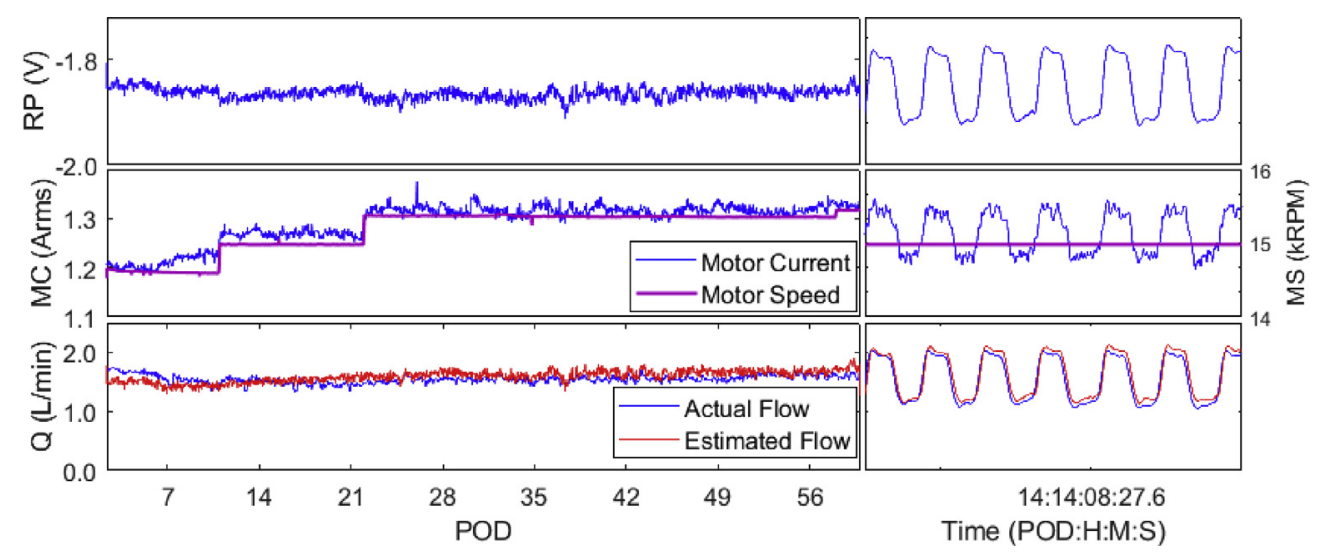

FIGURE E1. Flow rate estimation accuracy using the PediaFlow rotor position signal, motor current, and motor speed. Because of the fully magnetically levitated suspension, the rotor position signal used for the virtual zero power levitation control is analogous to the pressure drop across the pump and therefore provides an additional parameter (in addition to pump speed and motor current) to enhance flow rate estimation. The estimated flow rate for the 60-day PF4-S10 implant was within $6 \%$ of the actual flow rate as measured by the perivascular ultrasonic flow probe on the pump outflow tract. This feature will greatly simplify the instrumentation required for physiologic (hemodynamic) control of the PediaFlow system when used clinically. $R P$, Rotor position; $M C$, motor current; $P O D$, postoperative day; $M S$, motor speed.

\section{APPENDIX E2}

\section{Third-Generation PediaFlow Surgical Methods}

The PF3 was implanted in a healthy lamb for 72 days in accordance with the Institutional Animal Care and Use Committee guidelines at the University of Pittsburgh. ${ }^{\text {E1 }}$ The pump was introduced into the circulation as an LV assist device, interposed between the $\mathrm{LV}$ and descending thoracic aorta. Surgical access was gained through a left thoracotomy, followed by heparinization for a target activated clotting time greater than 300 seconds. A modified wire-reinforced polyurethane cannula (18F DLP, Medtronic, Minneapolis, Minn) was inserted into the apex of the LV through a stab incision and secured with a sewing ring fashioned from thick surgical felt (PTFE, C.R. Bard, Murray Hill, NJ). The outflow from the PF3 was 6-mm diameter polyester vascular graft (Vascutek Ltd, Renfrewshire, Scotland, UK) anastomosed to the descending thoracic aorta using a partial occlusion clamp. The pump was operated at a fixed speed of 14.5 kilo RPM. The flow rate was measured via an ultrasonic transit-time flow probe (Transonic Inc, Ithaca, NY) attached to the outflow graft. Throughout the study, pump flow, power consumption, and carotid blood pressure were recorded. Hemorheology and serum chemistry values were collected daily to assess the biological impact of the pump on blood damage and organ function.

\section{Surgical Sham (Control) Studies}

Three "sham" implants were performed for an intended 28-day duration for the purpose of obtaining "control" biocompatibility data for the PediaFlow implantations. ${ }^{\text {E2 }}$ These sham surgical implants mimic a full PediaFlow implant study with the exception of device insertion and allow us to account for surgery and postoperative recovery on rheology, platelet activation, and other biocompatibility indices of interest. Because preoperative jugular venipuncture samples are prone to artifact from needle sticking an awake animal, ${ }^{\mathrm{E} 2}$ a jugular venous catheter was placed under general anesthesia 1 week before sham surgery for collection of baseline biocompatibility parameters (ie, platelet activation, plasma free hemoglobin, and fibrinogen).

For the sham surgical procedure, after intubation and induction of anesthesia, the existing venous catheter in the left jugular vein was replaced and an arterial catheter was inserted in the left carotid artery. The thorax was entered via a left, fourth interspace thoracotomy, and the LV apex and descending aorta were exposed. The animal was anticoagulated with heparin to maintain the whole blood activated clotting time at 1.5 to 2.0 times baseline. A lubricated sewing ring was fixed on the LV apex and a stab incision was made in the LV apex, which was then sutured closed. A 3-cm length of 6-mm diameter Gelweave (Vascutek Ltd, Renfrewshire, Scotland, UK) graft was connected in an end-to-side fashion to the descending thoracic aorta to duplicate the pump outflow graft and anastomosis site. The graft was then "tied off" to prevent graft material being in contact with the blood.

Surgery proceeded without any major complications, the animals recovered from anesthesia and were returned to the intensive care unit, where they were monitored for the duration of the study. Recovery and follow-up were uneventful with hemodynamic and respiratory parameters remaining within normal limits. During follow-up periods, the animals were cared for exactly as the 72-day animal implanted with the PF3. After meeting the intended 28-day study period, the 3 sham experiments were electively ended for gross necropsy examination (Table E4). 
TABLE E4. Summary of the surgical sham (control) in vivo ovine studies

\begin{tabular}{cccl}
\hline $\begin{array}{c}\text { Study } \\
\text { animal }\end{array}$ & $\begin{array}{c}\text { Weight } \\
(\mathbf{k g})\end{array}$ & $\begin{array}{c}\text { Length }(\mathbf{d}) \\
\text { actual/intended }\end{array}$ & \multicolumn{1}{c}{ Necropsy findings } \\
\hline Sham-S01 & 45 & $39 / 28$ & $\begin{array}{l}\text { 1. Two minor }(<2 \mathrm{~mm} \text { diameter }) \text {, surface infarcts on left kidney } \\
\text { 2. Two minor }(<2 \mathrm{~mm} \text { diameter }) \text {, surface infarcts on right kidney } \\
\text { Sham-S02 }\end{array}$ \\
Sham-S03 & 55 & $32 / 28$ & 1. Single minor $(<2$ mm diameter $)$, surface infarct on right kidney \\
\hline
\end{tabular}

\section{APPENDIX E3 \\ Fourth-Generation PediaFlow In Vivo Developmental Summary}

A total of $11(n=11)$ in vivo ovine studies were performed with the PF4 pumps to develop, assess, and refine the implantable peripherals in addition to evaluating device hemodynamics and biocompatibility (Table E2). The initial 9 implants led to the parabolic-inflow cannula and outflow graft assembly design used together in the most recent implants (PF4-S10, PF4-S11) that are presented in the article.

\section{Pump Connectors}

Introduced with the PF4 prototypes was a compact, toolless, "quick-connect" coupling used with both the inflow cannula and the outflow graft assembly. Consisting of a nitinol-wire retaining clasp on the pump mating face and a flanged inlet/outlet adapter, attachment or removal of the cannula/graft is achieved by depressing the loop to concentrically deform the 2 guidewires that hold the radial flange in place (Figure E2, A). After initial wet-to-wet connections during surgical implantation were less than successful (Figure E2, B), a reduced flange diameter adapter was used for the PF4-S04 and subsequent implants that eliminated difficulties with nonseated pump connections (Figure E2, C).

\section{Outflow Tract Assembly}

As described in Table E5, 3 outflow assembly iterations were implanted in conjunction with the PF4 in vivo studies. Although previous-generation PediaFlow studies used polyester-based outflow grafts (including the 72-day PF3S01 implant), concerns about commercial availability and patency led to the selection of an ePTFE-based graft for the initial PF4 implants. Despite evaluating 2 different
ePTFE styles, continuing issues with excessive fluid and plasma protein loss (ie, "graft weep") led to the decision to return to the Gelweave grafts previously used successfully.

\section{Inflow Cannula}

Continuing the transition from modified, off-the-shelf, commercial hardware to PediaFlow-specific implantable components, a bevel-type inflow cannula was developed, modeled after the EXCOR LV drainage cannula (Table E6). Limited by premature ventricular suction or myocardial occlusion of the inlet tip, perioperative efforts to gain adequate drainage led to kinking of the inflow cannula evident at study termination (Figure E3).

After extensive redesign and ex vivo testing, ${ }^{\text {E3 }}$ the new suction-resistant parabolic-type inflow cannula, depicted in Figure 2, $B$, in the main article, was used in studies PF4-S10 and PF4-S11 with great success.

\section{Hemocompatibility Findings}

Despite the repeated challenges with the implantable peripherals in vivo, hemocompatibility as measured by plasma-free hemoglobin remained below $20 \mathrm{mg} / \mathrm{dL}$ for 7 of the 9 preliminary implants (Figure E4).

\section{E-References}

E1. Antaki JF, Ricci MR, Verkaik JE, Snyder ST, Maul TM, Kim J, et al. PediaFlow Maglev ventricular assist device: a prescriptive design approach. Cardiovasc Eng. 2010;1:104-21.

E2. Johnson CA, Wearden PD, Kocyildirim E, Maul TM, Woolley JR, Ye SH, et al. Platelet activation in ovines undergoing sham surgery or implant of the second generation PediaFlow pediatric ventricular assist device. Artif Organs. 2011; 35:602-13.

E3. Griffin MT, Grzywinski MF, Voorhees HJ, Kameneva MV, Olia SE. Ex vivo assessment of a parabolic-tip inflow cannula for pediatric continuous-flow VADs. Asaio J. 2016;62:600-6. 

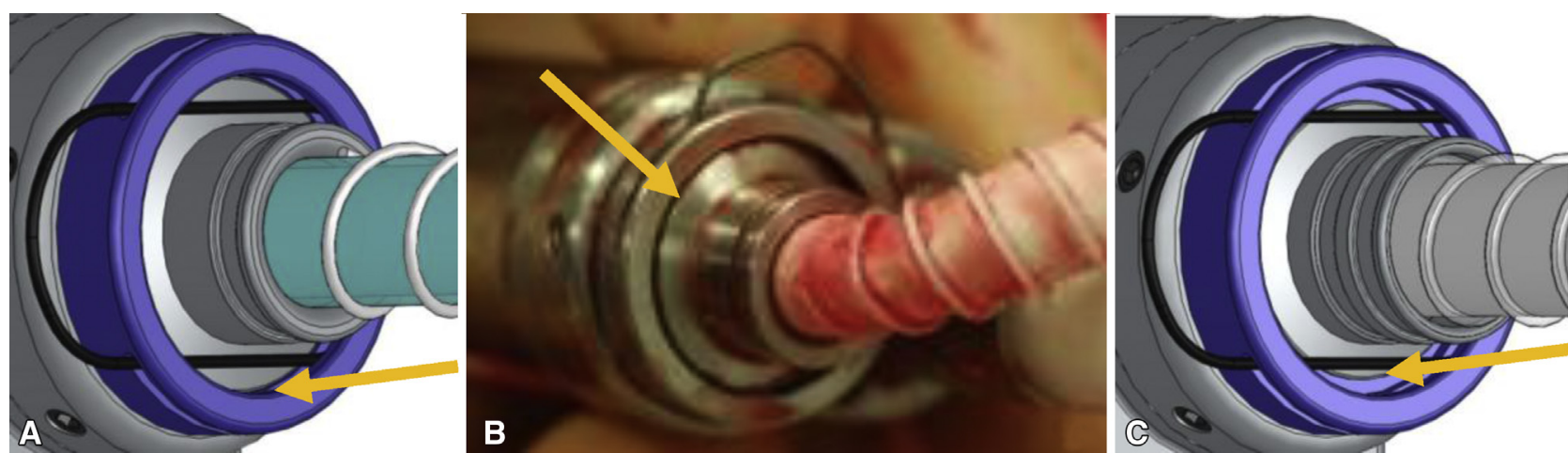

FIGURE E2. The PF4 quick-connect attachment mechanism: The initial full-flange design was difficult to attach (A) and prone to misalignment in vivo (B). C, The revised design with a smaller flange size to ease insertion past the guidewires.

TABLE E5. Outflow graft iterations used for the 11 fourth-generation PediaFlow implants

\begin{tabular}{lcll}
\hline & \multicolumn{2}{c}{ Outflow graft } & \\
\cline { 2 - 3 } Prototype & ID $(\mathbf{m m})$ & \multicolumn{1}{c}{ Material } & Modifications/external strain relief \\
\hline Bard ePTFE & 5.0 & Thin-wall ePTFE & - \\
SEAL-PTFE & 6.0 & Dual-layer, extraluminally gelatin-sealed ePTFE & $\begin{array}{l}\text { Reduced pump connector flange diameter } \\
\text { 8-mm MAXIFLO ePTFE Wrap }\end{array}$ \\
Gelweave & 6.0 & Gelatin-impregnated polyester & 8-mm MAXIFLO ePTFE Wrap \\
\hline
\end{tabular}

Bard ePTFE (5-mm Flex Thinwall Small Beading) is a product of Bard Peripheral Vascular (Tempe, Ariz). SEAL-PTFE (standard-wall, external spiral support), MAXIFLO (standard-wall, external solid-PTFE spiral support), and Gelweave are products of Vascutek Ltd (Renfrewshire, Scotland, UK). ePTFE, Expanded polytetrafluoroethylene.
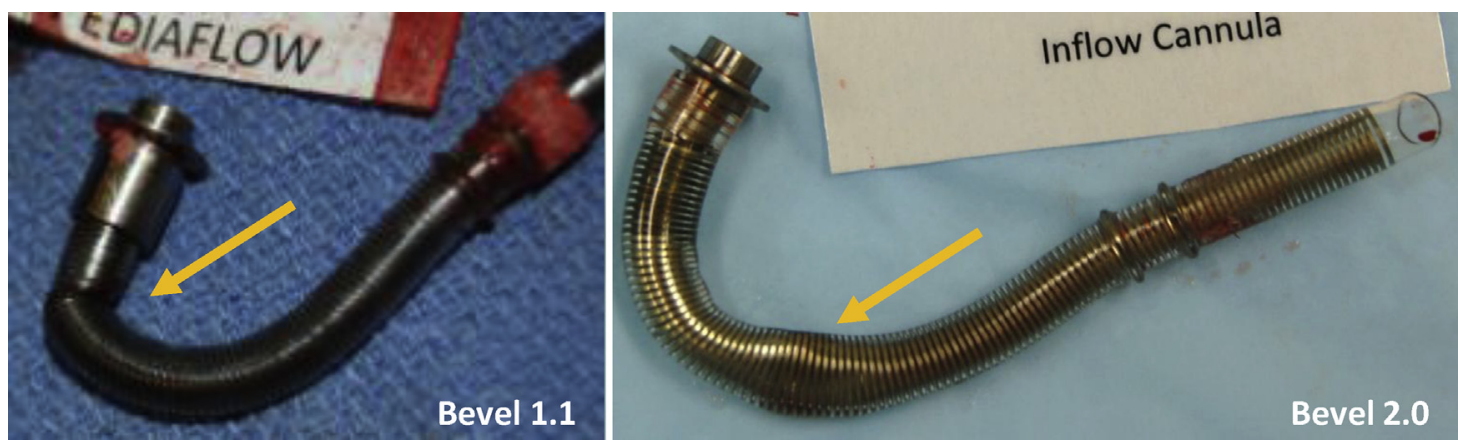

FIGURE E3. Example images of the inflow kinking phenomenon experienced with the bevel-type inflow cannulae from PF4-S06 (left) and PF4-S09 (right). 
TABLE E6. Inflow cannula prototypes used for the PF4 in vivo implants

\section{Prototype}

(inlet geometry)

Fenestrated

Bevel

Bevel

Bevel
Iteration

1.0
Design features

Modified 22F commercial venous drainage

Custom glue-fixed apical sewing ring

Single-stage multiport/caged-tip

Right-angle wire-reinforced body

Nitinol, round-wire reinforced polyurethane

Blunt-tip inlet opening

Preattached, fixed-depth, rotating sewing ring

Reduced pump connection flange diameter

316 SS, flat-wire reinforcement

Increased bend angle

Graded strain relief at pump connector

316 SS reinforced U-shaped inlet opening

Removable, variable depth, tool-less sewing ring

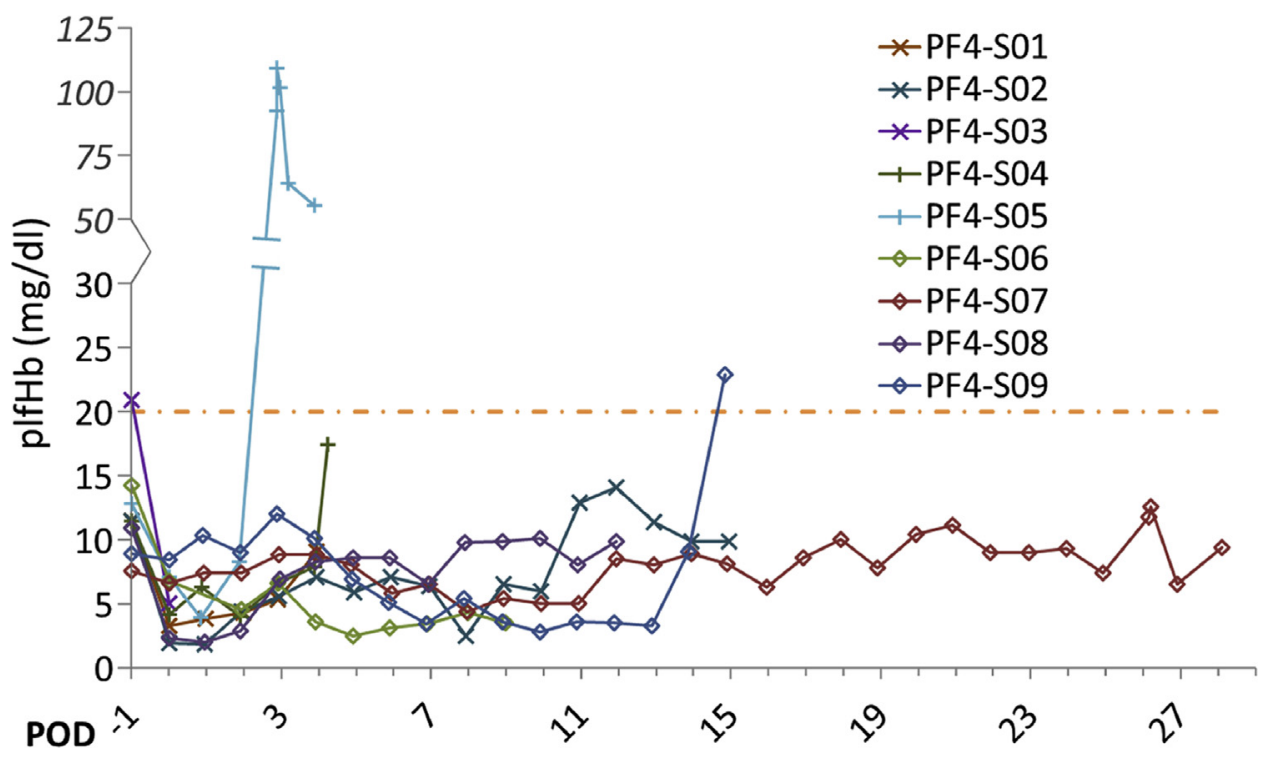

FIGURE E4. Plasma-free hemoglobin values for the initial in vivo PF4 implants. plfHb, Plasma-free hemoglobin; $P O D$, postoperative day; $P F 4$, fourthgeneration PediaFlow. 